\title{
Historiografía y curaduría: relatos visuales a partir de imágenes de archivo*
}

\author{
HISTORIOGRAPHY AND CURATORSHIP: VISUAL STORIES FROM ARCHIVAL IMAGES
}

HISTORIOGRAFIA E CURADORIA: RELATOS VISUAIS A PARTIR DE IMAGENS DE ARQUIVO

\section{Equipo TRansHisTor(ia) \\ (Camilo Andrés Ordóñez Robayo** y María Sol Barón Pino***)}

Cuadernos de Música, Artes Visuales y Artes Escénicas

/Volumen 13- Número 2 / Julio - Diciembre de 2018

/ ISSN 1794-6670/ Bogotá, D.C., Colombia / pp. 147-173

Fecha de recepción: 3 de mayo de 2017

Fecha de aceptación: 27 de noviembre de 2017

Disponible en línea: 1 de junio de 2018

doi: 10.11144/javeriana.mavae13-2.hycr

* Artículo de investigación derivado de los proyectos de investigación curatorial Múltiples y originales. Arte y cultura visual en Colombia: años 70 (Vicerrectoría Académica de la Pontificia Universidad Javeriana y Fundación Gilberto Alzate Avendaño) y Rojo y más rojo: producción gráfica y acción directa (IV Premio de Curaduría Histórica, 2010, Fundación Gilberto Alzate Avendaño). El equipo TransHisTor(ia) está conformado desde 2008 por Camilo Andrés Ordóñez Robayo y María Sol Barón Pino.

* $\quad$ Maestro en artes plásticas por la Universidad Nacional de Colombia y magíster en Estudios Artísticos por la Facultad de Artes ASAB de la Universidad Distrital Francisco José de Caldas. Profesor investigador del Departamento de Artes Visuales de la Pontificia Universidad Javeriana, perteneciente al grupo de investigación Pedagogía, Tecnología y Sociedad en las Artes Visuales. Profesor de la Facultad de Artes ASAB. Artista y curador, integrante del Colectivo Maski. ORCID: 0000-0002-0293-3045

** Maestra en artes plásticas por la Universidad de los Andes y magíster en Historia y Teoría del Arte y la Arquitectura por la Universidad Nacional de Colombia. Profesora investigadora del Departamento de Artes Visuales de la Pontificia Universidad Javeriana, perteneciente al grupo de investigación Pedagogía, Tecnología y Sociedad en las Artes Visuales.

ORCID: 0000-0002-2785-5872 


\section{Resumen}

El desarrollo de propuestas curatoriales a partir de la elaboración de fondos documentales que se constituyen en archivos resulta común hoy y enlazan campos como la museografía, la curaduría y los procesos artísticos. La práctica curatorial nos ha posibilitado confrontar la elaboración del relato histórico para elaborar pesquisas que conducen a la elaboración y consolidación de fondos documentales de imágenes que redundan en lo visual y que, caracterizados en torno a un archivo, permiten establecer hipertextos de contenido que se vuelcan en la apuesta museográfica como un campo de lectura abierto para el observador. Este artículo busca presentar la articulación creativa de procesos historiográficos y postulados curatoriales alrededor de la elaboración de relatos alternativos a la historia y la historia del arte. A partir de la reflexión sobre el desarrollo de dos proyectos de investigación y curaduría histórica (Múltiples y originales: arte y cultura visual en Colombia: años 70 [2010] y Rojo y más rojo. Taller 4 Rojo: producción gráfica y acción directa [2012]) presentamos cómo hemos procurado asimilar contenidos que son arrojados por repertorios visuales, parcialmente articulados iconográfica o iconológicamente, que buscan confrontar la cultura visual a través de la relectura que implica el contexto expositivo.

Palabras clave: historiografía; curaduría; cultura visual; historia del arte; Taller 4 Rojo; memoria.

\section{Abstract}

The development of curatorial proposals based on the elaboration of documentary collections that are constituted in archives is common today and it links fields such as museography, curatorship and artistic processes. The curatorial practice has allowed us to confront the elaboration of the historical narrative to conduct research that lead to the elaboration and consolidation of documentary collections of images that result in something visual and that, characterized around a file, make it possible to establish content hypertexts that focuses on the museographic commitment as an open reading field for the observer. This article seeks to present the creative articulation of historiographical processes and curatorial postulates around the elaboration of alternative stories to history and the art history. Based on the reflection on the development of two research projects and historical curatorship (Múltiples y originales: arte y cultura visual en Colombia: años 70 [2010] and Rojo y más rojo. Taller 4 Rojo: producción gráfica y acción directa [2012]) we present how we have tried to assimilate contents resulting from visual repertoires, partially articulated in iconographic or iconologic terms, that seek to confront the visual culture through the re-reading involved in the expository context.

Keywords: Historiography; curatorship; visual culture;

history of art; 4 Rojo Workshop; Memory.

\section{Resumo}

O desenvolvimento de propostas curatoriais a partir da elaboração de fundos documentais constituídos em arquivos é comum hoje em dia e enlaçam campos como a museografia, a curadoria e os processos artísticos. A prática curatorial nos possibilita confrontar a elaboração do relato histórico para elaborar pesquisas que levam à elaboração e consolidação de fundos documentais de imagens que redundam no visual e que, caracterizados em torno a um arquivo, permitem estabelecer hipertextos de conteúdo orientados ao compromisso museográfico como um campo de leitura aberta para o observador. Este artigo busca apresentar a articulação criativa de processos historiográficos e postulados curatoriais ao redor da elaboração de relatos alternativos à história e a história da arte. A partir da reflexão sobre o desenvolvimento dos projetos de pesquisa e curadoria histórica (Múltiples y originales: arte y cultura visual en Colombia: años 70 [2010] e Rojo y más rojo. Taller 4 Rojo: producción gráfica y acción directa [2012]), apresentamos o modo como temos procurado assimilar conteúdos que são resultado de repertórios visuais, parcialmente articulados iconográfica o iconologicamente, que buscam confrontar a cultura visual através da releitura implicada no contexto expositivo.

Palavras-chave: historiografia; curadoria; cultura visual; história da arte; Oficina 4 Rojo; memória. 
El desarrollo de propuestas curatoriales a partir de la elaboración de fondos documentales ${ }^{1}$ que se constituyen en archivos resulta común hoy y enlaza campos de circulación que se refieren a la museografía, la curaduría y los procesos artísticos. Tras la exhibición de archivos, puede identificarse una "zaga" de antecedentes que bien pueden situarse en diferentes prácticas artísticas y culturales que se desataron desde las primeras vanguardias, se desarrollaron durante el siglo XX y coinciden con tentativas metodológicas de historiadores del arte contemporáneos al desenvolvimiento del arte moderno como Aby Warbug y a disposiciones discursivas como la emprendida por Walter Benjamin en su proyecto inacabado en torno a los pasajes. ${ }^{2}$

En años recientes, la revisión sobre el aporte historiográfico de Aby Warburg ha motivado y estimulado la compresión de "escrituras visuales" que permiten comprender y abordar la curaduría y la exposición como un dispositivo narrativo y argumental; un índice de este fervor es la reimpresión y revisión de estudios realizados por Aby Warburg, entre los que, cada vez con mayor insistencia, se incluyen los registros fotográficos realizados en su biblioteca y dirigidos a exponer los paneles en los que algunos conjuntos de imágenes definidos por él mismo buscaban sustentar sus ideas. Tal es el caso del Atlas Menmosyne, editado para el público hispanohablante por la editorial Akal en 2010, donde el formato mismo de la publicación se justifica en la necesidad de reproducir tales fotografías y privilegiar la circulación de estas imágenes como "escrituras visuales" en compañía de las anotaciones realizadas por Warburg. ${ }^{3}$

En ese orden de ideas, comprendemos la práctica curatorial como una plataforma desde la que es posible confrontar la elaboración del relato histórico, y la cual nos ha permitido elaborar pesquisas que conducen a la elaboración y consolidación de fondos documentales que redundan en lo visual y que, caracterizados en torno a un archivo, permiten establecer hipertextos de contenido que se vuelcan en la apuesta museográfica como un campo de lectura abierto para el observador. Al mismo tiempo, la puesta en escena de un conjunto de artefactos, imágenes, documentos y obras nos ha permitido, posteriormente, construir relatos que proponen llevar a la escritura una lectura sobre los contenidos intrínsecos a cada uno de estos índices, así como reflexionar sobre aquellas conexiones y tensiones que surgen en la convergencia de ellos en un mismo lugar: la exposición.

A partir de nuestra experiencia como investigadores en historia del arte colombiano, y como curadores en el desarrollo de los proyectos Múltiples y originales. Arte y cultura visual en Colombia: años 70 (2010) y Rojo y más rojo. Taller 4 Rojo: producción gráfica y acción directa (2012-2014), este artículo busca presentar la articulación creativa de postulados curatoriales a partir de procesos historiográficos alternativos a las concepciones tradicionales de historia e historia del arte. La práctica curatorial nos ha permitido asimilar contenidos arrojados por repertorios visuales, que buscan confrontar la cultura visual a través de la relectura que implica el contexto expositivo, por lo cual, además, nos interesa presentar algunas conclusiones de la investigación sobre Taller 4 Rojo en torno a las maneras en que la producción del colectivo ha activado y dinamizado, de diversas formas, la memoria ante sus públicos contemporáneos: los del pasado y los del presente.

Por lo anterior es que las fuentes principales para este artículo son artefactos, la mayoría de carácter artístico y visual, que hicieron parte del relato visual de las dos curadurías mencionadas. ${ }^{4}$ Nos interesa acudir a un dispositivo altamente visual como en una curaduría, ya que, como en el teatro de la memoria, ${ }^{5}$ esta permite mostrar significados inéditos que surgieron de 
la conexión de imágenes heterogéneas, al menos, a primera vista. En suma, nos interesa concebir las imágenes como medio autónomo de conocimiento y reactivación de la memoria, sin que dependan, como ha sido tradicional, de un cuerpo teórico que las describa y comprenda.

En ese orden de ideas, vamos a referir dos experiencias en relación con proyectos de investigación en torno a la historia del arte y la cultura visual en Colombia, enfocados en la formulación de una propuesta curatorial que, en su proceso, nos ha resultado como una plataforma creativa para constituir archivos y derivar, posteriormente, en ejercicios historiográficos volcados en la elaboración de documentos. En primer lugar, queremos señalar el contexto general del proceso de Múltiples y originales. Arte y cultura visual en Colombia: años 70, y luego nos concentraremos en detalles relacionados con la construcción de un archivo, la identificación de fuentes y campos de circulación durante el proceso que vivimos en torno a Rojo y más rojo. Taller 4 Rojo: producción gráfica y acción directa.
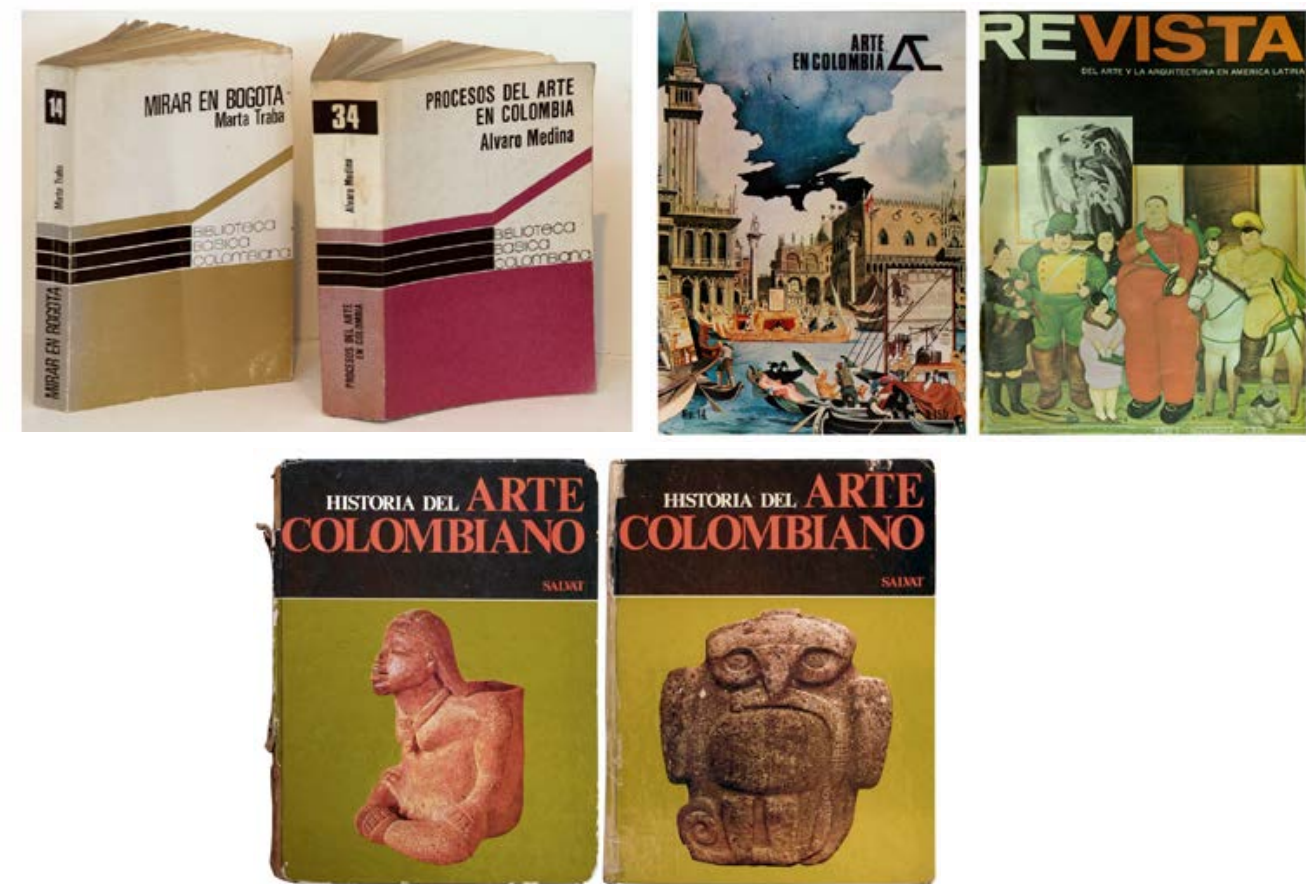

Figura 1. Publicaciones de arte en Colombia en 1970

Fuente: Tomos 14 y 34 Mirar en Bogotá (Traba, 1976) y Procesos del arte en Colombia (Medina, 1978) de la Colección Biblioteca Básica Colombiana. Diseño de Marta Granados.

Portada y contraportada de la revista Arte en Colombia (n. $\left.{ }^{\circ} 14,1981\right)$

Portada y contraportada de Revista del Arte y la Arquitectura (año 1, n. $^{\circ} 3,1978$ )

Tomos 1 y 2 de la enciclopedia Historia del arte colombiano publicada por Editorial Salvat, segunda edición (1977).

La década de 1970 es un periodo sumamente fértil para los estudios de arte en Colombia. Esto obedece a varias razones, en primer lugar, en aquella época se consolidó un significativo grupo de museos dedicados a la promoción del arte moderno y contemporáneo, lo cual favoreció una mayor circulación de la producción artística, ${ }^{6}$ así como propició la ampliación de nuevos actores y prácticas, entre ellas, la curaduría, que permitieron la producción de diversas publicaciones relativas a exposiciones de carácter contemporáneo o histórico. Paralelamente, se 
estimuló la crítica y la investigación histórica sobre el arte colombiano, y surgieron proyectos de gran envergadura que hoy resultan clásicos y se mantienen aún vigentes, como la Historia del arte colombiano de Salvat (Barón y Ordóñez, 2015) dirigida al público general y que alcanzó una popularidad inusual en nuestro contexto. ${ }^{7}$

En segundo lugar, y como consecuencia de la descripción anterior, este ha sido un periodo constantemente revisitado en años recientes: se han realizado varias curadurías para exposiciones que apuntan a ese periodo, o bien retrospectivas panorámicas, o bien temáticas, al tiempo que ha proliferado la producción académica sobre problemas de aquella época, lo cual ha ampliado la literatura existente y ha otorgado visibilidad a otras prácticas y actores. ${ }^{8}$ En suma, la década de 1970 ha resultado fundamental para la actividad académica en el campo del arte, tanto en su propio presente como cuatro décadas después (véanse figuras 1 y 2 ).
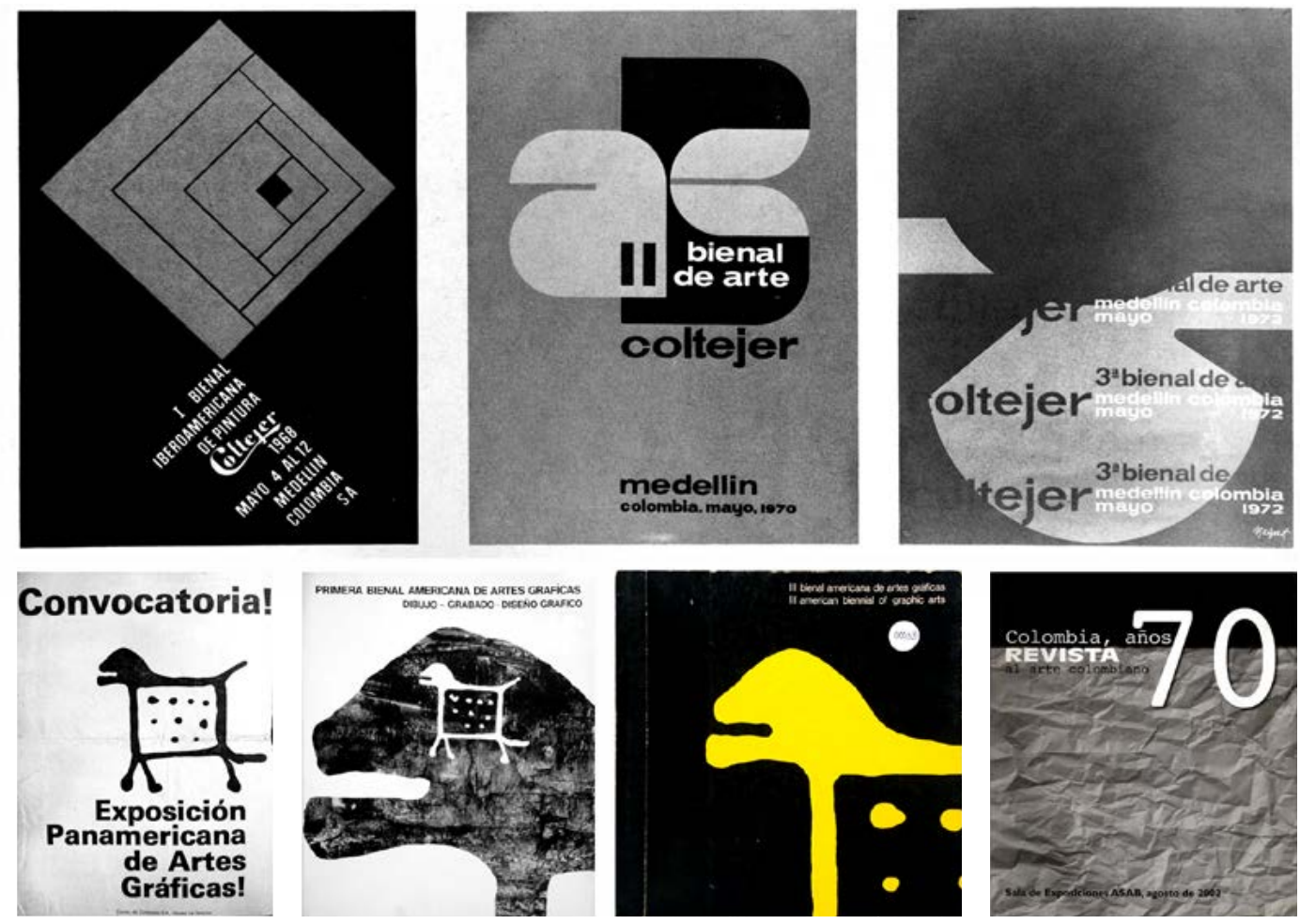

Figura 2. Carteles de la I, II, y III Bienal de Arte Coltejer en Medellín.

Fuente: Revista del Arte y la Arquitectura (vol. 2, n. ${ }^{\circ} 6,1981$, pp. 14 y 15)

Convocatoria! Exposición Panamericana de Artes Gráficas. Pauta publicada en El Espectador (20 de septiembre de 1970). Archivo Museo La Tertulia (Cali). Catálogos de la I y II Bienal Americana de Artes Gráficas $(1971,1973)$. Biblioteca Museo de Arte Moderno de Bogotá

Portada del catálogo Revista Arte en los años setenta. Carmen María Jaramillo (2004). Academia Superior de Artes de Bogotá.

Tal fenómeno tiene una correspondencia con el desarrollo de la visualidad y producción artística durante esa década. Muchos artistas de entonces acudieron a fuentes visuales que no participaban del campo de la historia del arte o del rol didáctico que esta ocupaba en las escuelas de arte; ${ }^{9}$ de hecho, varios artistas partieron de imágenes que circulaban en medios de comunicación masivos para formular sus procesos (Beatriz González o Taller 4 Rojo, para mencionar un par), insertaron sus producciones en estos campos de circulación (Álvaro Barrios) y se acercaron a las lógicas comunicativas y visuales de medios y lenguajes particulares como el cine, la fotografía y las artes gráficas (Óscar Muñoz, Miguel Ángel Rojas, Ever Astudillo, Gustavo Zalamea y Luis Paz, por ejemplo). En gran medida, el desarrollo 
tecnológico en torno a la visualidad y producción editorial fue una circunstancia que propició tal productividad en el campo artístico y, en consecuencia, estimuló unas formas de producción artística en diálogo con el original múltiple y la matriz fotográfica que resultaron fértiles para el desarrollo de nuevas prácticas artísticas (véase figura 3).
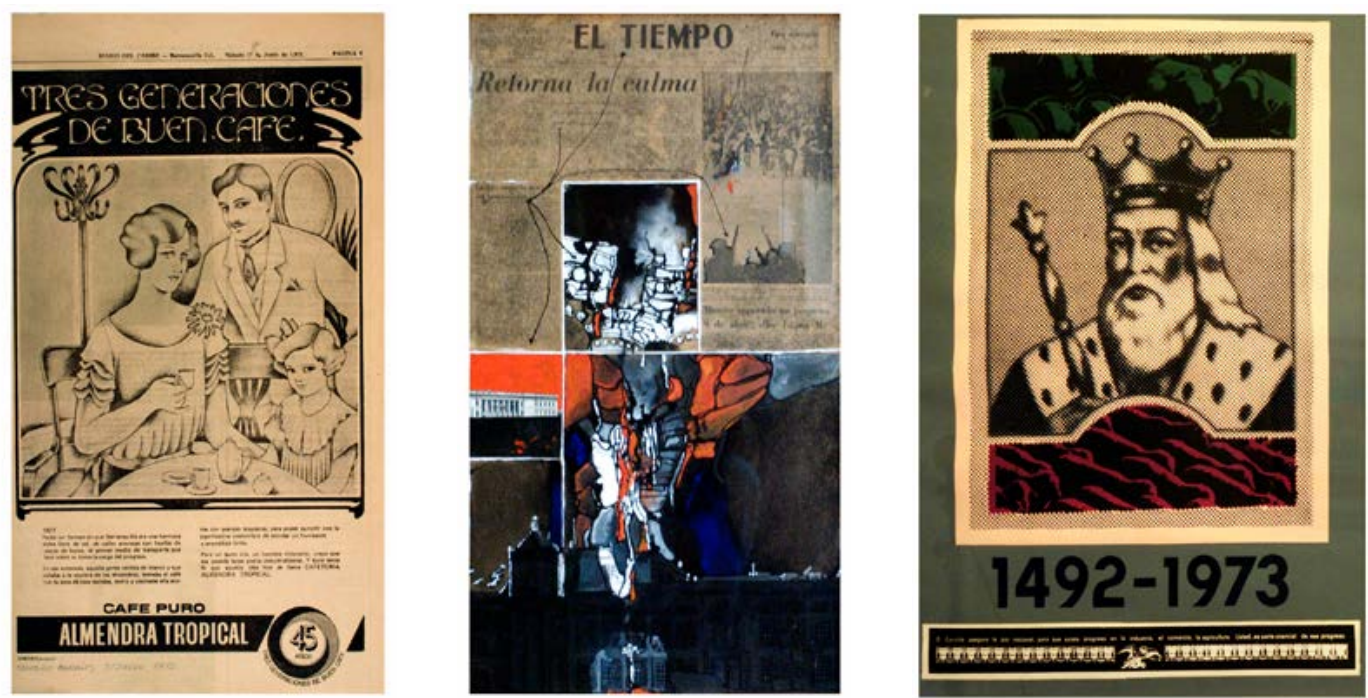

Figura 3. Tres generaciones de café, de Álvaro Barrios (1972); Retorna la calma, de Gustavo Zalamea (1977): Yo soy el rey y amo la ley, de Luis Paz (1973). Fuente: Ejemplar de la serie Tres generaciones de buen café (Álvaro Barrios, 1972). Impresión offset sobre papel, $39 \times 23 \mathrm{~cm}$ c/u. Publicado en Diario del Caribe (Barranquilla, 17 de junio de 1972). Colección Museo de Arte Moderno de Bogotá

Retorna la calma (Gustavo Zalamea, 1977). Dibujo y collage sobre página del diario El Tiempo, $70 \times 70 \mathrm{~cm}$. Colección particular.

Yo soy el rey y amo la ley (Luis Paz, 1973). Fotoserigrafía sobre papel, $100 \times 70 \mathrm{~cm}$. Colección Museo de Arte Moderno de Bogotá
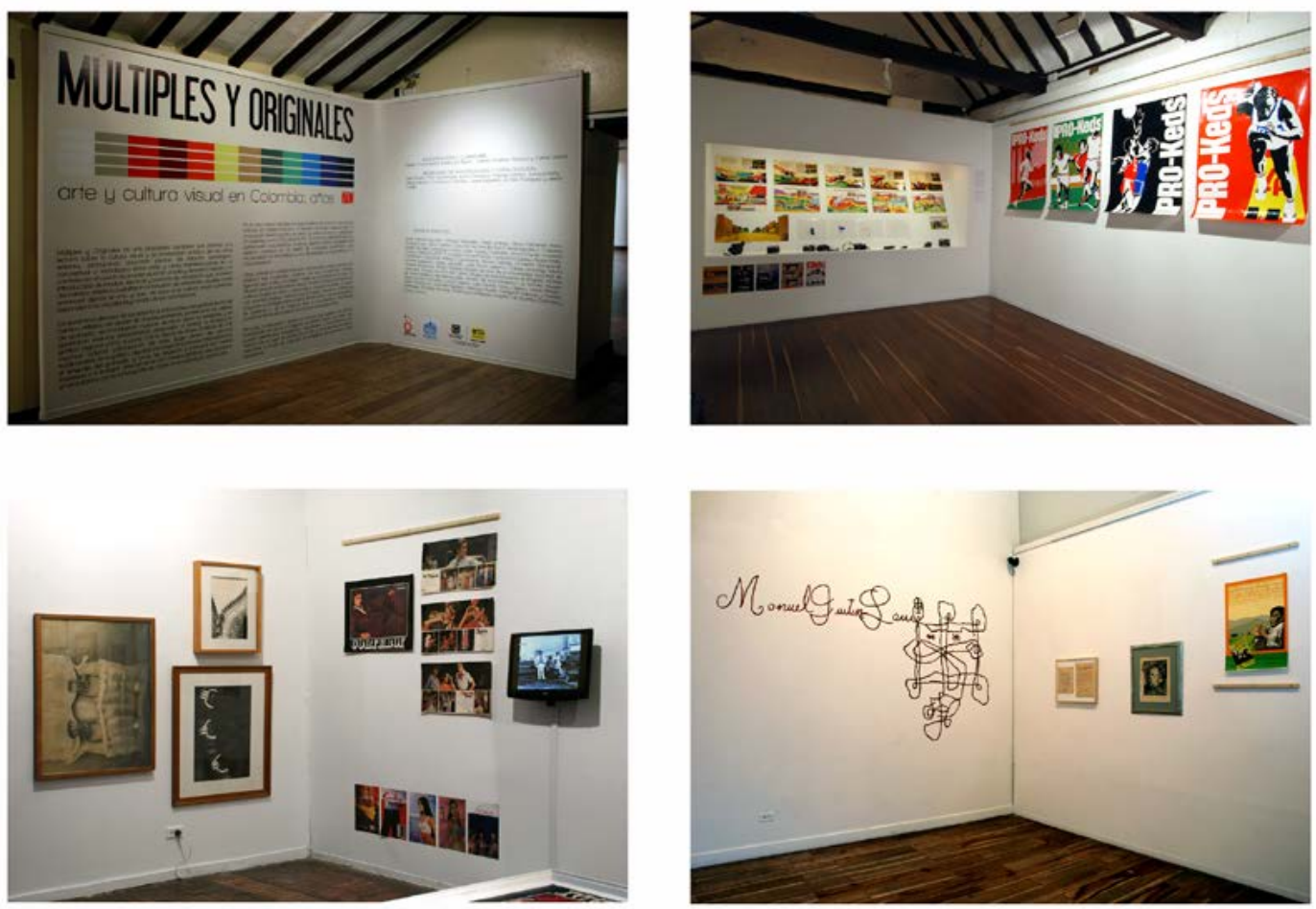

Figura 4. Vistas de la curaduría Múltiples y originales. Arte y cultura visual en Colombia: años 70

Fuente: Vistas parciales de la exposición Múltiples y originales. Arte y cultura visual en Colombia: años 70 realizada en la Fundación Gilberto Alzate Avendaño en Bogotá (2010). Curaduría: equipo TRansHisTor(ia). Fotografía: Camilo Ordóñez Robayo, Archivo equipo TRansHisTor(ia). 
En suma, se trató de un aumento de la economía visual, una amplificación en las formas de producción e intercambio visual que pesó fuertemente en formas de construcción de realidad y cotidianidad, y que puede resumirse en transformaciones básicas como la popularización de la policromía en los medios impresos, la aparición de la televisión en color, el aumento de la producción cinematográfica local y proyecciones de cine (con la consecuente multiplicación de cinemas en grandes ciudades), la formalización y modernización de la propaganda de Estado e institucional y la renovación y contextualización de prácticas creativas de la publicidad (véase figura 4).

Tal amplitud de la economía visual creó repertorios y relatos visuales contundentemente insertados en la cotidianidad y en la producción artística del periodo. Esa fue la hipótesis que orientó la formulación de Múltiples y originales, una curaduría que, en su proceso de preparación, nos sirvió como plataforma historiográfica para articular y proponer un panorama acorde con esa cuestión, sustentado en la producción visual misma; una suerte de hipertexto visual que comprendió un vasto repertorio visual donde se involucraron el arte y otras manifestaciones visuales de manera horizontal.

Por supuesto, partimos de la producción artística y, en particular, de aquella que trazaba clara o tangencialmente un vínculo con el original múltiple y la matriz fotográfica. De esta operación inicial, derivamos un conjunto de temas o problemas reiterativos en diferentes formas de producción visual con los que conformamos un conjunto de "nichos" compuestos por imágenes de diverso proceder que dieron forma a la museografía.
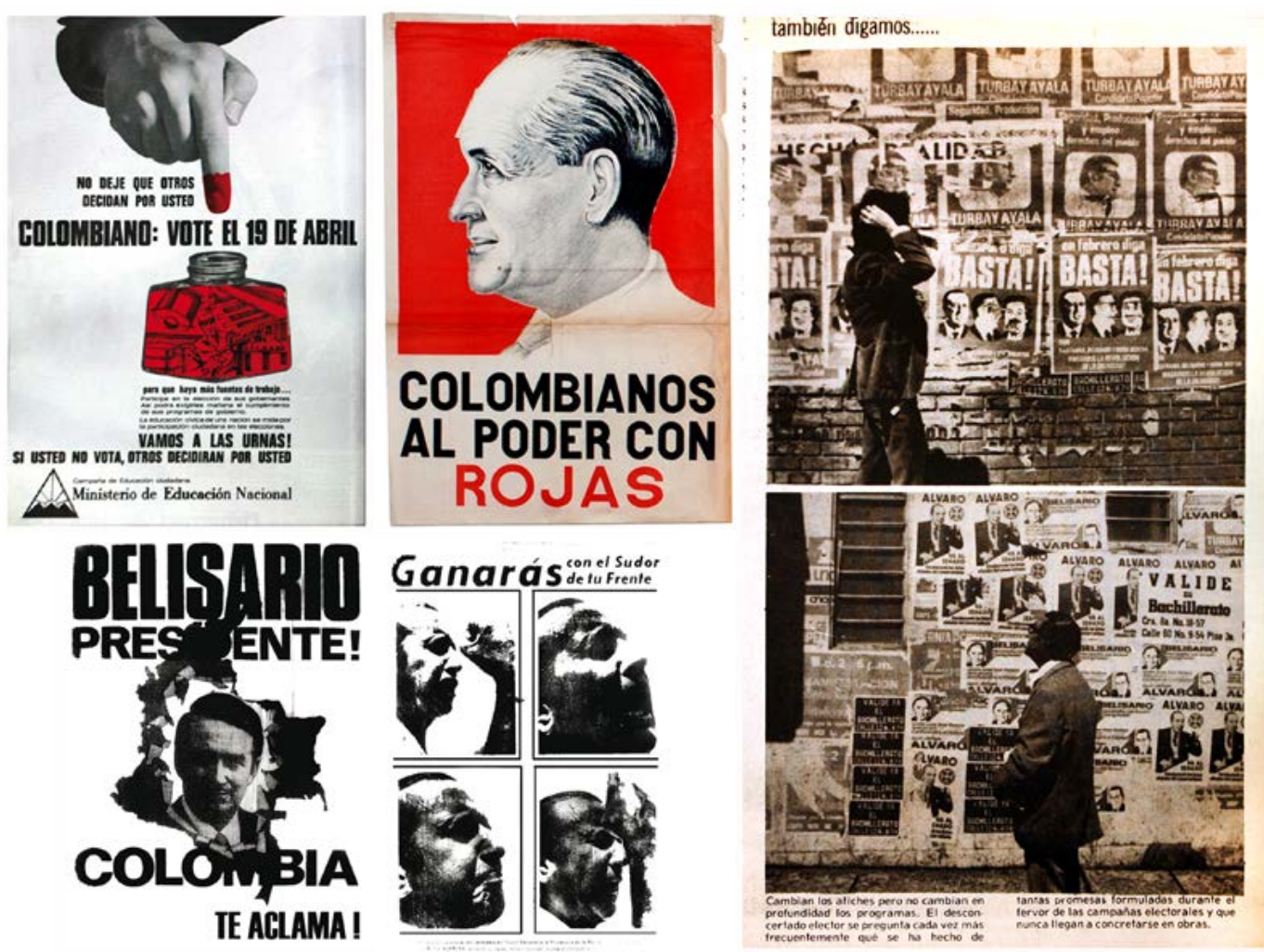

Figura 5. Pautas publicitarias estatales e independientes en prensa, carteles de campaña presidencial de 1970 y fotografías de empapeladas en la calle durante la campaña presidencial de 1974.

Fuente: Colombiano: Vote el 19 de abril. Propaganda del Ministerio de Educación Nacional publicada en Revista Cromos (n. ${ }^{\circ} 2725,16$ de marzo de 1970, p. 28).

Colombianos al poder con Rojas. Propaganda publicada en Semanario Alerta (5 de abril 1970).

Belisario presidente Colombia te aclama. Propaganda publicada en El Espectador (19 de abril de 1970, p. 9A).

Ganarás con el sudor de tu frente. Propaganda publicada en El Espectador (16 de abril 1970, p. 1A).

Registro de publicidad política pegada sobre algunos muros en calles de Bogotá (Revista Flash, n. ${ }^{\circ}$ 4, segunda etapa, 15 de febrero, 1978, p. 16) 
Para mencionar un par de ejemplos, identificamos la producción visual en torno a las elecciones presidenciales de 1970, que hizo evidente un uso de la publicidad política impresa, práctica inédita hasta entonces en Colombia, y las formas en que tales campañas figuraron en prensa o buscaron otras estrategias de circulación y que, a su vez, generaron prácticas artísticas. $\mathrm{O}$, por ejemplo, encontramos que los dispositivos de representación visual del país a través de una idílica imagen rural fueron estimulados por la propaganda sobre el sector turístico desarrollada por la Corporación Nacional de Turismo y, también, por la producción cinematográfica desarrollada bajo el estímulo de la denominada Ley de Sobreprecio, todo esto dentro de un escenario orientado ideológicamente por el Estado colombiano (Barón y Ordóñez, 2011a) (véanse figuras 5 y 6).
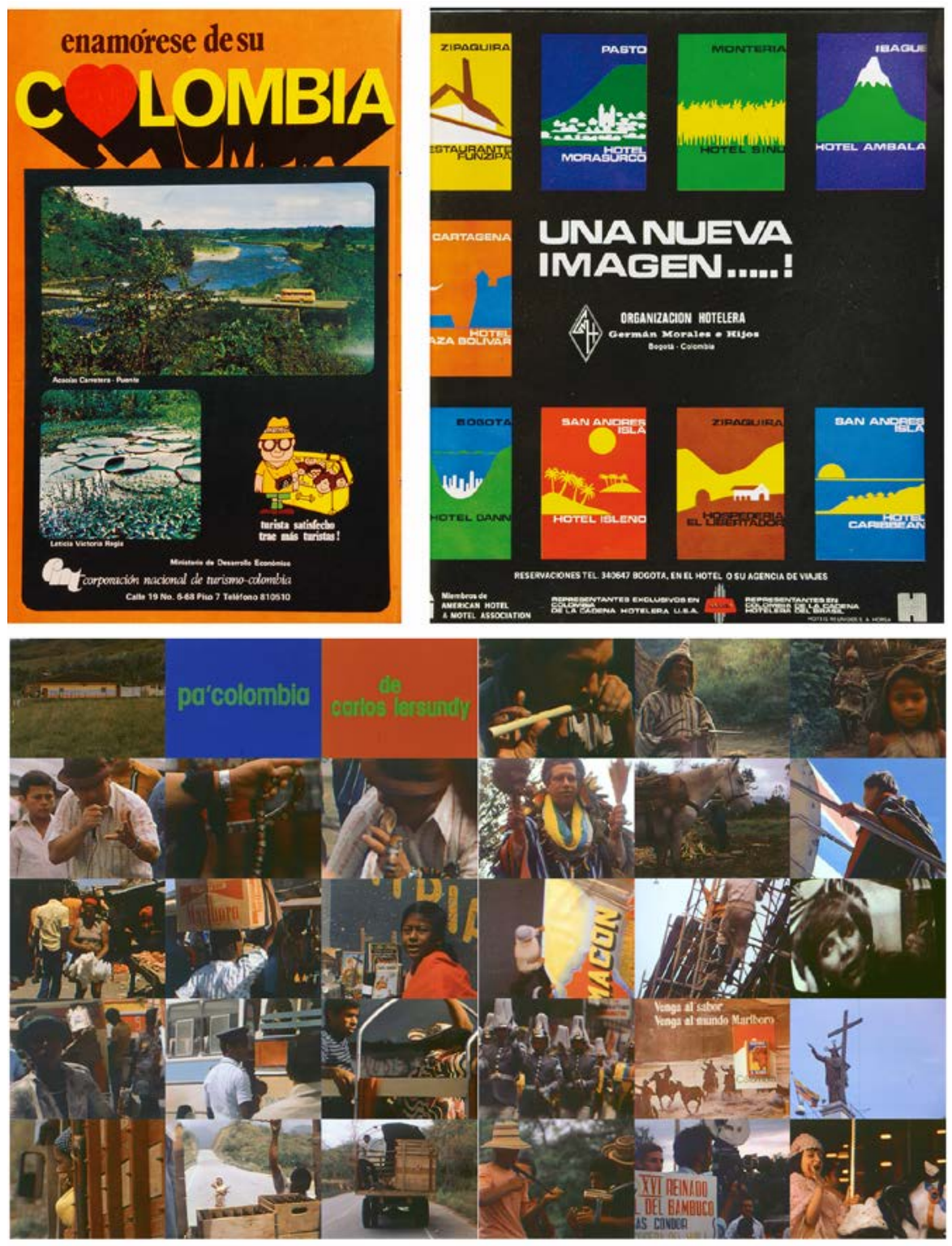

Figura 6. Pautas publicitarias en Revista Colombia (1973), Cromos (ca. 1973) y fotogramas del ensayo audiovisual Pa' Colombia, Carlos Lersundy (1979).

Fuente: Enamórese de su Colombia. Corporación Nacional de Turismo. Propaganda publicada en la revista Colombia, 1973. Una imagen nueva...! Publicidad de la organización Hotelera Germán Morales e Hijos Ltda., publicada en revista Diners (n. ${ }^{\circ}$ 67, febrero de 1967).

Selección de cuadros del cortometraje Pa' Colombia. Director: Carlos Lersundy (1971-1979. 16 mm, color, 14 minutos). 
Meses después de presentar la curaduría, elaboramos un documento que, parcialmente, dio punto final a esta suerte de "modo historiográfico" curatorial, como si el archivo configurado en nuestra investigación sustentara los hilos de la curaduría y aquella —dispuesta museográficamente- detonara una serie de conexiones visuales que sustentan un relato posible sobre coyunturas de aquel contexto registradas a través de una cultura visual.

Visto hoy, Múltiples y originales nos resulta como una hoja de ruta. No como un relato teleológico sobre un problema cerrado, estricto o particular, y tampoco como un popurrí para facilitar una revisión de temas y campos sin medida o aleatorio, sino como un repertorio visual que nos ha permitido identificar problemas de representación, imaginación y circulación particulares, cifrados en arquetipos dentro de un campo de economía visual ampliada,

al que necesariamente estamos ligados de manera generacional. Tras Múltiples y originales comprendimos la disposición museográfica de la curaduría como el momento en que la suma de fuentes visuales, su simultaneidad espacial, logra evidenciar relaciones para liberar contenidos, de modo que la práctica curatorial resulta en plataforma teórico-práctica para el desarrollo de la investigación.

\section{EN BUSCA DE TALLER 4 ROJO}

Un capítulo derivado de aquel proceso fue Rojo y más rojo, un proyecto en el que, nuevamente, nos propusimos la elaboración de un archivo amplio como estructura funcional para propiciar un relato visual sobre la acción y producción de un colectivo de artistas denominado Taller 4 Rojo.

Taller 4 Rojo es considerado uno de los primeros colectivos artísticos en Colombia; estuvo activo durante la década de 1970, e hicieron parte de él los artistas Nirma Zárate, Diego Arango, Umberto Giangrandi, Carlos Granada, Fabio Rodríguez Amaya, y el fotógrafo Jorge Mora, entre otros. Su sede principal fue un taller de artes gráficas en el histórico barrio La Candelaria en el centro de Bogotá, donde se realizaron obras artísticas (colectivas e individuales) y trabajos gráficos de difusión realizados por encargo o en apoyo a diferentes sectores sociales. Entre los aportes de Taller 4 Rojo, cuenta la incorporación de la fotoserigrafía como lenguaje artístico en Colombia y el establecimiento de una escuela de artes gráficas donde otros se formaron artística y políticamente. De manera simultánea, para los integrantes de Taller 4 Rojo, el acompañamiento a algunos movimientos sociales a través de la difusión visual era fundamental y, por lo mismo, fue renunciando rápidamente a la participación dentro de espacios artísticos convencionales. Algunas estampas realizadas por Taller 4 Rojo fueron directamente dispuestas sobre muros en espacios públicos, algunas vallas y carteles hicieron parte de movilizaciones y manifestaciones sociales y otras imágenes fueron realizadas en acompañamiento directo a movimientos sindicales, indígenas y campesinos. En un momento, Taller 4 Rojo se dividió, algunos de sus integrantes siguieron trabajando con la denominación colectiva Taller 4 Rojo y otros conformaron el equipo Causa Roja; ambos grupos continuaron apoyando sectores sociales en labores de difusión por algún tiempo. Taller 4 Rojo, en los últimos años, ha cobrado un gran interés en varios proyectos de investigación sobre arte colombiano (véase figura 7). 

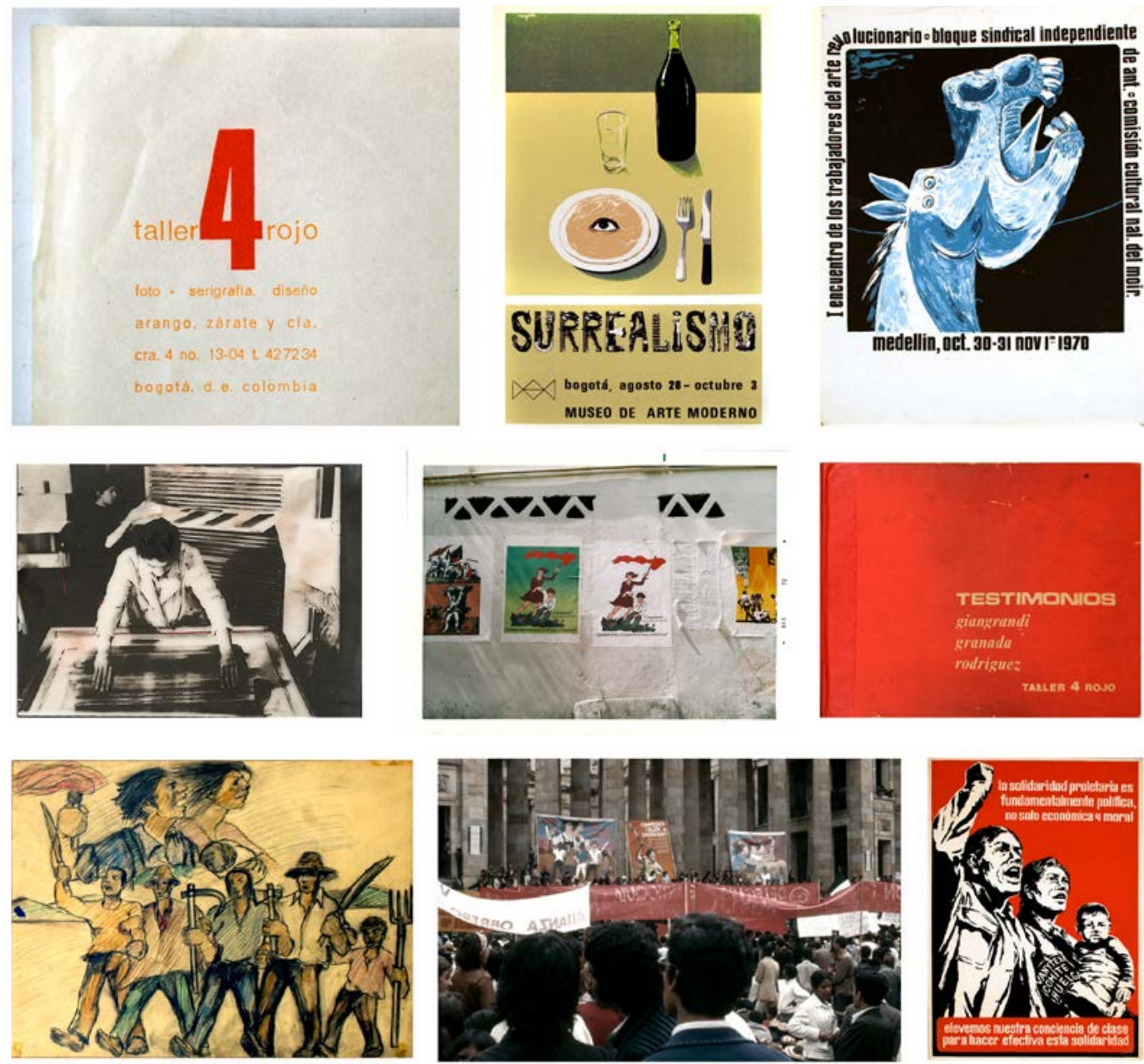

Figura 7. Papelería de Taller 4 Rojo, cartel de difusión cultural y política, documentos sobre el taller, bocetos y circulación de estampas y pancartas del colectivo en el espacio público y marchas, carpeta de grabado y carteles de apoyo a la huelga de Vanitex.

Fuente: Membrete de papelería de Taller 4 Rojo (ca. 1970). Tipografía sobre papel, $28 \times 21 \mathrm{~cm}$

Cartel comisionado por el Museo de Arte Moderno de Bogotá para la difusión de la exposición Surrealismo. Taller 4 Rojo (1971). Fotoserigrafía sobre papel, $70 \times 50 \mathrm{~cm}$ (revés sellado).

Cartel comisionado por el MOIR para la difusión del I Encuentro de los Trabajadores del Arte Revolucionario. Taller 4 Rojo (atribuido). Fotoserigrafía sobre papel, $69.5 \times 50 \mathrm{~cm}, 1970$

Fotografía en la Escuela Taller 4 Rojo. Grupo Taller 4 Rojo (ca. 1972). Fotografías lith, $6 \times 8.5 \mathrm{~cm}$

Intervención en la Universidad de los Andes con obras del Grupo Taller 4 Rojo. 1972 . Fotografía a color $35 \mathrm{~mm}, 9 \times 12 \mathrm{~cm}$.

Carpeta testimonios. Taller 4 Rojo (Umberto Giangrandi, Carlos Granada y Fabio Rodríguez Amaya), 1974. Impresión offset sobre cartón plegado, $35 \times 50 \mathrm{~cm}$

Boceto de pancarta para manifestación. Carlos Granada/Grupo Taller 4 Rojo (ca. 1973). Lápiz de color sobre papel, $47 \times 36 \mathrm{~cm}$

Manifestación en la Plaza de Bolívar en Bogotá. Jorge Mora (1974). Fotografía $35 \mathrm{~mm}$.

Cartel de difusión sobre la huelga de Vanitex. Taller Causa Roja (Diego Arango y Nirma Zárate y otros), ca. 1976. Serigrafía sobre papel, $70 \times 50 \mathrm{~cm}$.

Las anteriores son algunas de las acepciones generales sobre la trayectoria de Taller 4 Rojo aportadas desde tiempo atrás por la literatura disponible sobre el campo del arte en Colombia; basta cruzar algunas de estas fuentes y estas acepciones empiezan a ordenarse con facilidad (Barón y Ordóñez 2011b). No obstante, hasta 2009, cuando emprendimos la investigación sobre el colectivo, la producción visual de Taller 4 Rojo se encontraba muy parcialmente reseñada en algunos títulos de historia del arte en Colombia. Justamente, algunas de estas publicaciones en las que aparece registrada esta producción fueron realizadas durante la década de 1970, lo cual demuestra el impacto que la producción del grupo tuvo, incluso en su contexto inmediato. ${ }^{10}$

Ahora bien, al inicio de la investigación, buena parte de la literatura conocida coincidía en nombrar la vinculación del colectivo con movimientos sociales, pero el registro de sus actividades se había concentrado en identificar un limitado número de estampas en 
fotoserigrafía y en señalar la trayectoria de los integrantes del grupo en relación con escenarios tradicionales del campo artístico, entre ellos, el capítulo "La figuración política" de German Rubiano (1977) publicado en Historia del arte colombiano (Bogotá: Salvat, 1975 ) y en el libro de María Elvira Iriarte Historia de la serigrafía en Colombia (1986).

Entonces, asumimos que indagar el tipo de producción que Taller 4 Rojo propició hace cuarenta años implicaba, no solo considerar la dinámica de trabajo colectivo que supone el ámbito de un taller gráfico o comprender las circunstancias en las que surgió un grupo de artistas identificados con las demandas de varios movimientos sociales, sino que era fundamental indagar unas prácticas artísticas que desde el acompañamiento a movimientos sociales se extendieron más allá del campo artístico y, en consecuencia, rastrear los escenarios de circulación en los que mayormente tomó parte esa producción visual de Taller 4 Rojo, parcialmente enunciada por la historiografía. ${ }^{11}$ Este último aspecto fue una inquietud central que encaminó la toma de decisiones como autores de la curaduría (véanse figuras 8 y 9).
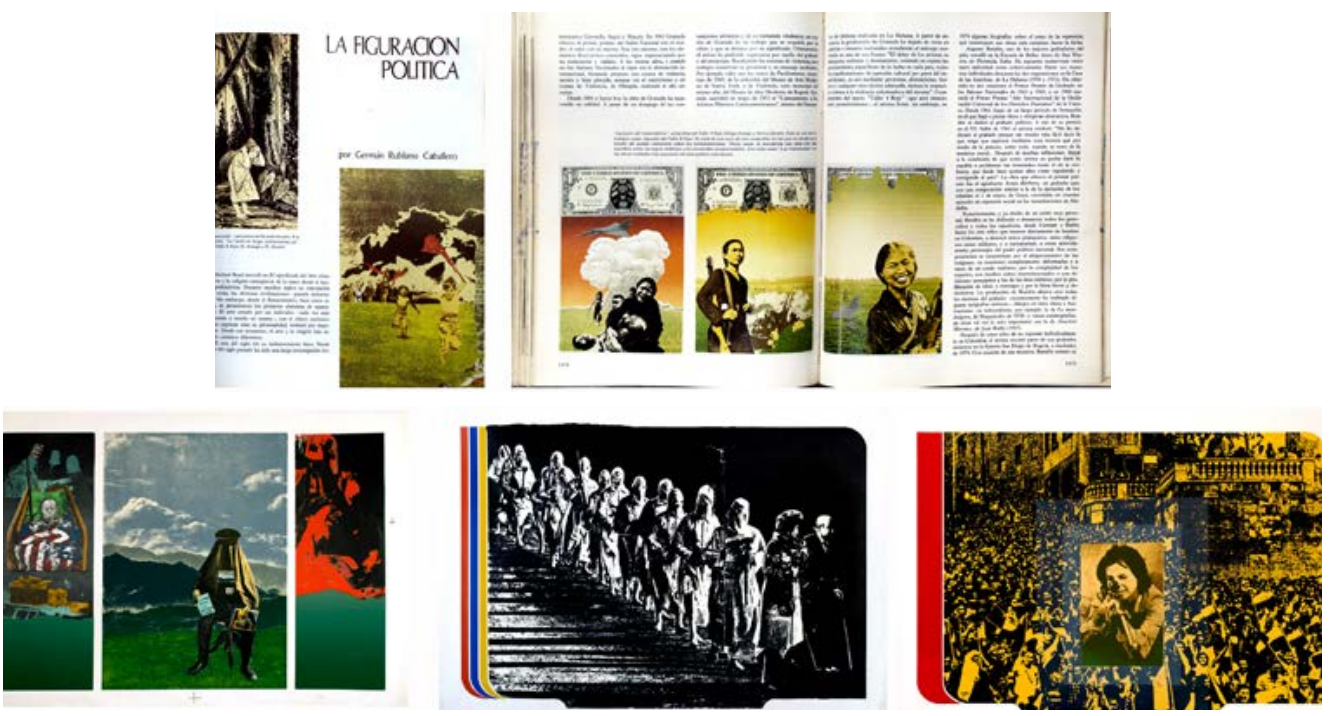

Figura 8. Estampas de Taller 4 Rojo

Fuente: Páginas 1563, 1570 y 1570 en el tomo V de la primera edición de la enciclopedia Historia del arte colombiano, publicada por editorial Salvat (1975). Serie América I. Diego Arango y Nirma Zárate/Grupo Taller 4 Rojo (1973). Fotoserigrafía sobre papel, $70 \times 100 \mathrm{~cm}$.
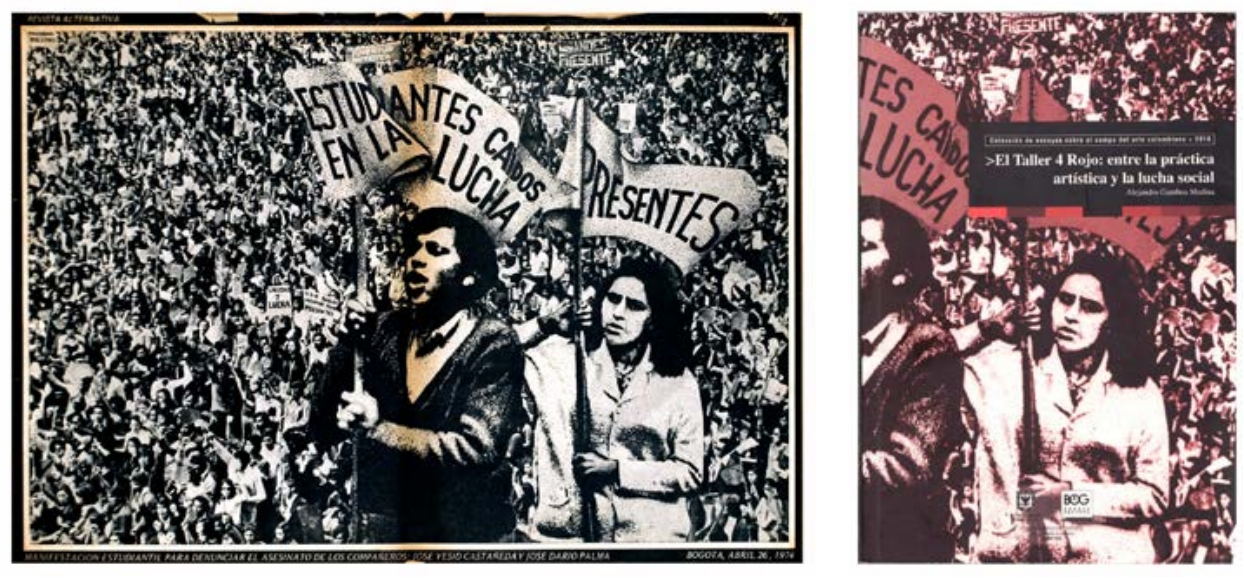

Figura 9. Cartel de Taller 4 Rojo.

Fuente: Cartel para la revista Alternativa $\left(n .^{\circ}\right.$ ) en apoyo al movimiento estudiantil. Diego Arango y Nirma Zárate/Grupo Taller 4 Rojo

(1974). Impresión offset sobre papel, $50 \times 35 \mathrm{~cm}$.

Portada de El taller 4 Rojo: entre la práctica artística y la lucha social (Alejandro Gamboa, 2011, Instituto Distrital de las Artes). 
Emprendimos la investigación para conformar una exposición de Taller 4 Rojo, a pesar del escepticismo que se manifestaba comúnmente respecto de esa posibilidad, ya que representaba una operación de búsqueda y ubicación de un fondo visual indeterminado y muy parcialmente conocido. Nuestro fin no era constituir un catálogo razonado o archivo extenso que constituyera un inventario veraz e ineludible sobre la producción gráfica identificable de Taller 4 Rojo para sintetizarlo; por el contrario, nos concentramos en comprender la suma de estas imágenes como un vehículo de contenidos que permitiría contrastarlas entre sí como fuentes visuales y hablar con algunos interlocutores sobre imágenes particulares y recuperar contenidos sobre sus instancias o propósitos creativos y de circulación; de modo que este archivo, más que la suma de un objeto de estudio, serviría como un vehículo para identificar los campos de circulación que tuvo la producción hallada o de la que tuvimos noticia. En parte, porque los estudios preexistentes habían enunciado algunas formas de circulación derivadas de la producción de Taller 4 Rojo acorde con sus intereses sociales, pero no se habían propuesto identificar estas dinámicas de circulación; y más aún, consideramos que, al reconocer los campos de circulación de Taller 4 Rojo, podríamos reconstituir un repertorio visual para comprender el curso histórico de lo que fuimos denominando el campo circundante de Taller 4 Rojo. ${ }^{12}$

Consideramos que, al determinar esos campos de circulación, podríamos establecer virajes en la constitución e intereses de Taller 4 Rojo y sus integrantes, pero, al mismo tiempo, para hacerlo, era necesario ubicar y comprender un repertorio ampliado de su producción. Así que, a través de las estampas, pruebas de impresión, bocetos, fotografías y otros documentos, que poco a poco encontramos en archivos de artistas vinculados a Taller 4 Rojo y de algunos amigos o colegas suyos, aumentamos lentamente ese pequeño conjunto de piezas reconocido historiográficamente (siete estampas recurrentemente citadas). En paralelo, realizamos entrevistas a los artistas, a sus amigos que también fueron activistas, así como a sindicalistas u obreros que conocieron el trabajo del colectivo y sus integrantes, con lo cual construimos una trama social de estos, sus prácticas y formas de creación y producción, con las que fue posible derivar un mapa de ciertos campos de producción, circulación y acción de Taller 4 Rojo.

Dentro del panorama ampliado que implicaron los estados parciales del material recopilado y documentado en un archivo digital que produjimos, se hicieron visibles recurrencias creativas centradas en la apropiación de imágenes extraídas de prensa u otros documentos o en la reinversión de motivos creados en Taller 4 Rojo de una composición a otra; en suma, ambos casos implicaban reiteraciones visuales. Paralelamente, aquel panorama dejaba ver aquellos anhelados campos de circulación que describían un proceso progresivo de desvinculación del campo del arte.

Encontramos que la frecuencia con que se manifestaban algunas imágenes y la proyección de su circulación en un campo diferente al del arte favorecieron la elaboración de relatos visuales como dispositivos de memoria, pues la producción de Taller 4 Rojo estuvo estrechamente ligada a una necesidad de reactivar figuras políticas del pasado, denunciar situaciones adversas a las luchas sociales contemporáneas en Colombia, participar de acciones directas y propiciar la representación directa de organizaciones activas en la década de 1970.

Por tanto, nos interesa reparar sobre tres dimensiones de la memoria presentes en la producción de Taller 4 Rojo, y que se hicieron visibles en la investigación curatorial. Nos referiremos, primero, a algunas piezas que operan explícitamente como dispositivos de 
memoria sobre luchas sociales a través de algunos personajes locales; segundo, a prácticas en las que el repertorio visual configurado por Taller 4 Rojo fue apropiado por organizaciones sociales; y tercero, a testimonios de actores sociales desvinculados del campo del arte que fueron aportados en la investigación o ante el archivo desplegado en la curaduría.

\section{CONMEMORACIONES}

Una vez logramos ampliar el repertorio de imágenes producidas en el campo circundante de Taller 4 Rojo, pudimos identificar una recurrencia creativa que implicaba la reiteración de imágenes de líderes o mártires locales vinculados a diferentes luchas sociales en Colombia; una operación que, dentro del repertorio visual de Taller 4 Rojo convencionalmente conocido, se había limitado a una estampa en fotoserigrafía con la figura de Camilo Torres, sacerdote que anticipa la teología de la liberación, fundador del movimiento político de oposición Frente Unido, y quien, tras la censura y una fuerte persecución, decidió renunciar a su vida civil y religiosa e integrarse a la lucha armada. Vale señalar que esta estampa es muy conocida, en parte, gracias a su inclusión en la enciclopedia Historia del arte colombiano (Salvat, 1975); sin embargo, allí aparece un segmento que no incluye la imagen del sacerdote insurgente (véase figura 10).

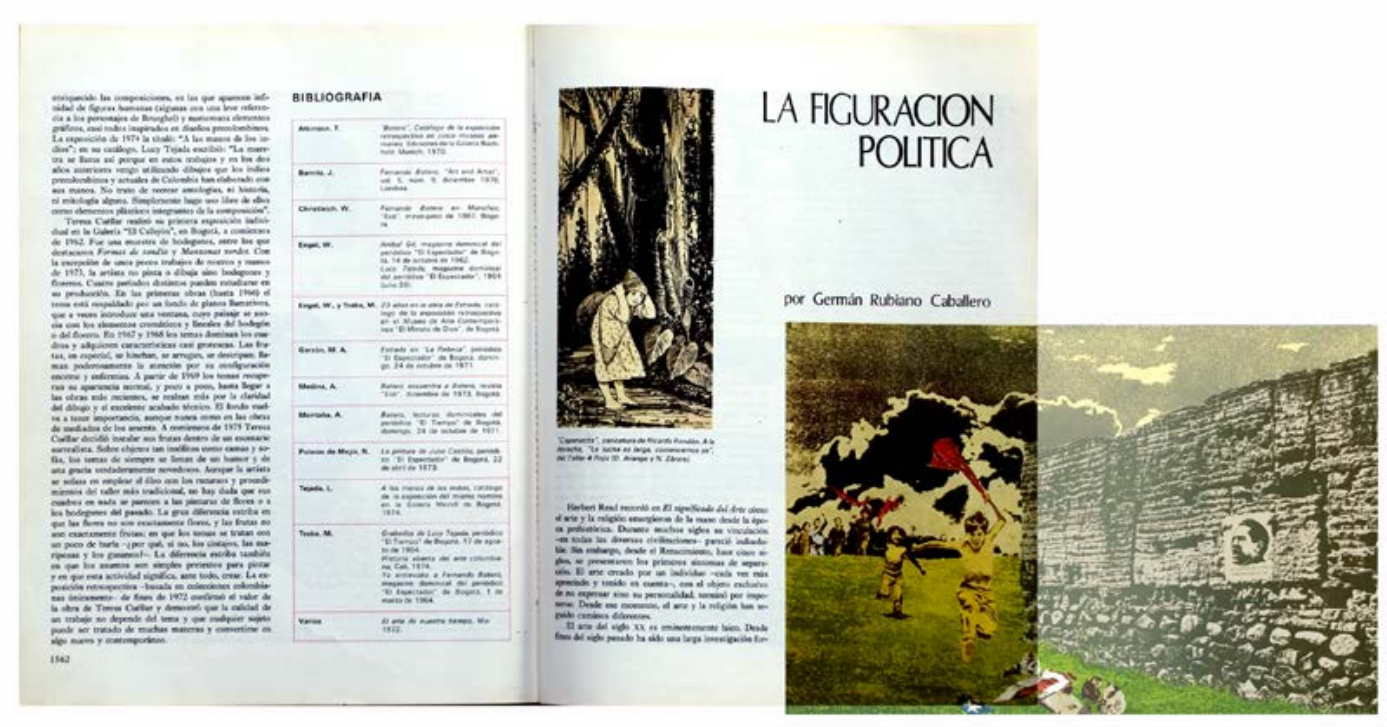

Figura 10. Página interior de la enciclopedia Historia del arte colombiano (Salvat, 1975)

Fuente: Páginas 1563 en el tomo V de la primera edición de la enciclopedia Historia del Arte Colombiano (Salvat, 1975).

Serie América IV. Diego Arango y Nirma Zárate/Grupo Taller 4 Rojo (1973). Fotoserigrafía sobre papel, $70 \times 100 \mathrm{~cm}$.

En ese nuevo repertorio visual, aparecieron figuras históricas como María Cano, líder del movimiento obrero durante la tercera década del siglo XX y cofundadora del Partido Socialista Revolucionario en 1926; líderes muertos recientemente como Manuel Quintín Lame, dirigente indígena que luchó durante el siglo XX contra formas modernas de sometimiento a los pueblos indígenas y en defensa de sus derechos sobre la tenencia colectiva de la tierra. Al mismo tiempo, se hicieron visibles otros mártires de la lucha social contemporáneos al proceso de Taller 4 Rojo como Gustavo Mejía, colaborador del movimiento indígena del 
departamento del Cauca, asesinado en 1974, y Luis Carlos Cárdenas, presidente de Sintradepartamento, organización abanderada del sindicalismo independiente, quien fue asesinado por fuerzas del Estado en 1973 (véase figura 11).
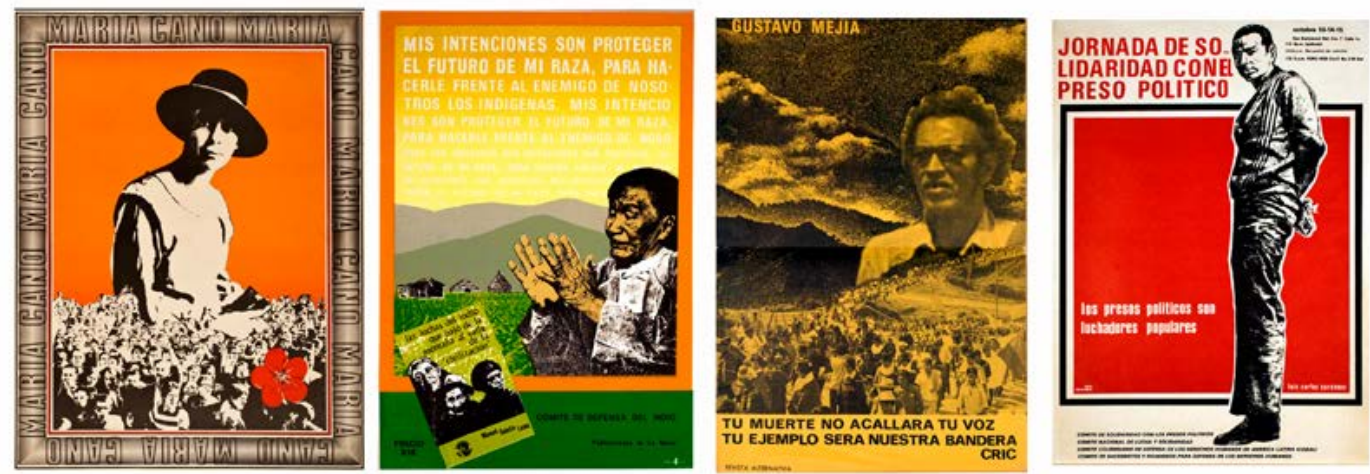

Figura 11. Carteles elaborados por el campo circundante de Taller 4 Rojo (1970-1976).

Fuente: La flor roja del trabajo. Homenaje a María Cano. Diego Arango y Nirma Zárate/Taller 4 Rojo (1971). Reproducción facsimilar, $70 \times 50 \mathrm{~cm}$. Cartel para la difusión del libro de Quintín Lame Las luchas del indio que bajó de la montaña al valle de la "civilización". Grupo Taller 4 Rojo (ca. 1973). Serigrafía sobre papel, $90 \times 65 \mathrm{~cm}$

Cartel para la Revista Alternativa (n. $\left.{ }^{\circ} 4\right)$ en homenaje a Gustavo Mejía. Diego Arango y Nirma Zárate/Taller 4 Rojo (1974). Impresión offset sobre papel, $50 \times 35 \mathrm{~cm}$. Archivo particular.

Cartel de difusión para Jornada de Solidaridad con el Preso Político. Taller Causa Roja (Diego Arango y Nirma Zárate), 1976. Impresión Offset sobre papel, $70 \times 50 \mathrm{~cm}$.

Vistos en conjunto, la figuración de estos personajes dentro de la producción generada en el campo circundante de Taller 4 Rojo implica un recorrido histórico sobre la presencia de esos líderes revolucionarios en las luchas de movimientos sociales de Colombia; recorrido que comienza con la invocación de María Cano y se prolonga hasta la enunciación de mártires caídos en luchas contemporáneas.
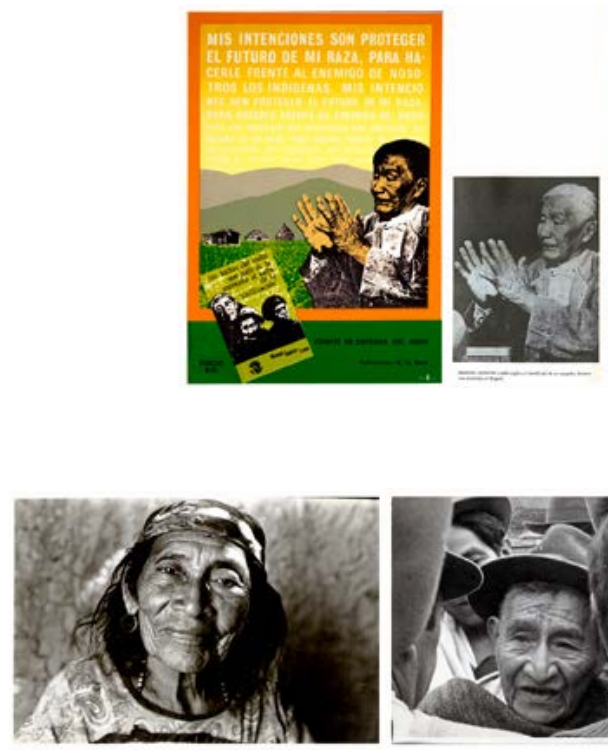
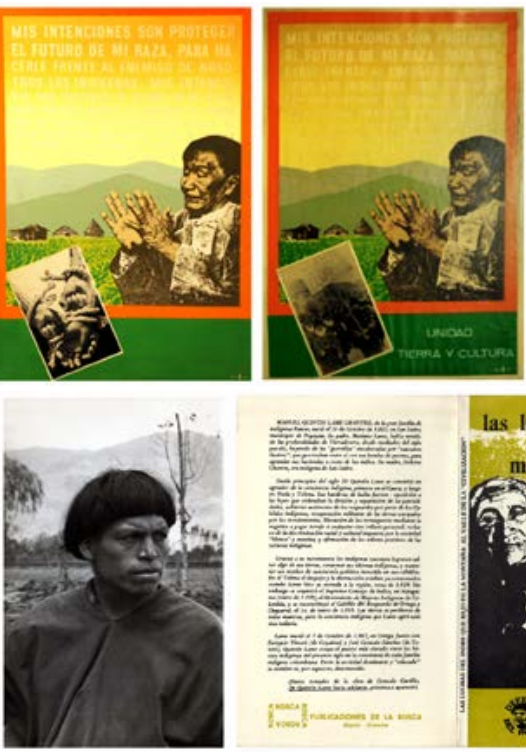

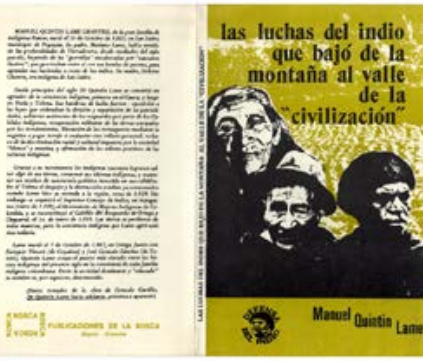

Figura 12. Versiones varias del cartel de difusión del libro de Las luchas del indio que bajó de la montaña al valle de la "civilización" (Bogotá: Rosca de Investigación y Acción Social, 1973), portada del libro y fuentes fotográficas usadas.

Fuente: Cartel para la difusión del libro de Quintín Lame Las luchas del indio que bajó de la montaña al valle de la "civilización". Grupo Taller 4 Rojo (ca. 1973). Serigrafía sobre papel, $90 \times 65 \mathrm{~cm}$.

Fotografía de Manuel Quintín Lame publicada en Las luchas del indio que bajó de la montaña al valle de la "civilización". Anónimo. Fotografía empleada en la carátula de Las luchas del indio que bajó de la montaña al valle de la "civilización" (Jorge Mora, ca. 1973). Fotografía en blanco y negro $35 \mathrm{~mm}, 12.5 \times 20.5 \mathrm{~cm}$.

Carátula para Las luchas del indio que bajó de la montaña al valle de la "civilización" (Jorge Mora/Grupo Taller 4 Rojo, 1973). Impresión offset sobre cartulina, $22 \times 14 \mathrm{~cm}$ 
En 1971, Diego Arango y Nirma Zárate elaboraron un cartel en offset sobre María Cano, en el que la imagen de la líder obrera resuena sobre una escena de protesta del movimiento obrero contemporáneo. En 1973, a seis años de la muerte de Quintín Lame, el grupo diseñó la portada de un libro con textos escritos por el líder indígena titulado Las luchas del indio que bajó de la montaña al valle de la "civilización", y también elaboró el cartel para su promoción. El libro y el cartel afirman visualmente el llamado a la unidad del movimiento indígena promulgado por Lame (véase figura 12).

En ese mismo año, 1973, el grupo diseñó una serie de fotoserigrafías claramente dedicadas a Camilo Torres Restrepo, en las que se le representa como líder de la lucha revolucionaria colombiana entre jóvenes y ciudadanos inconformes con la situación política y social. La más conocida muestra a un grupo de niños ondeando trapos rojos mientras patean los restos de emblemas estadounidenses. Al costado derecho, como pegado sobre el muro y en paralelo al rostro del niño que se ubica en primer plano, figura un cartel con el rostro de Camilo Torres y la frase "La lucha es larga, comencemos ya". La otra estampa, prácticamente inédita, plantea una narrativa visual en torno a la Proclama a los colombianos, documento con en el que el sacerdote hizo públicas sus razones para enlistarse en el Ejército de Liberación Nacional. La fotoserigrafía presenta un paisaje con una imponente montaña que se eleva a la derecha, mientras que, a la izquierda, un grupo de campesinos, con azadones y herramientas al hombro, caminan sobre el llano que se abre a las faldas del cerro. Otros recuadros muestran diferentes actores populares que participan en el proceso revolucionario y en el centro se halla un fragmento del texto que dio origen a la pieza (véase figura 13).
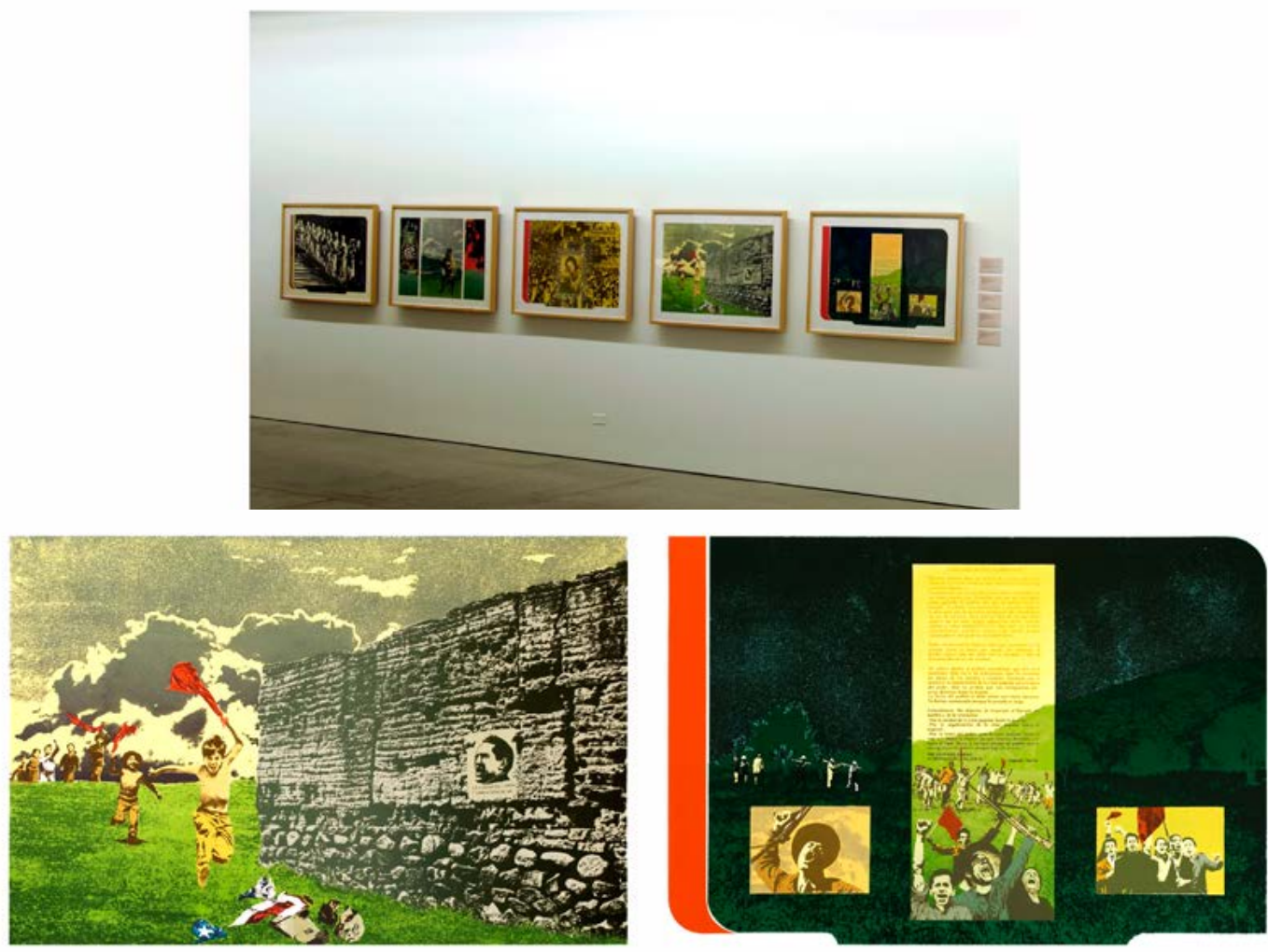

Figura 13. Estampas de la serie América 73 de Taller 4 Rojo, las dos de abajo inspiradas en el pensamiento de Camilo Torres. Fuente: Serie América I. Diego Arango y Nirma Zárate/Grupo Taller 4 Rojo (1973). Fotoserigrafía sobre papel, $70 \times 100 \mathrm{~cm}$.

Vista de la Serie América I, II, III, IV y V en la exposición Rojo y más rojo. Taller 4 Rojo: producción gráfica y acción directa, según la versión realizada para el Museo de Arte Moderno de Medellín (2013). Curaduría: equipo TRansHisTor(ia). Fotografía: Camilo Ordóñez Robayo, archivo TRansHisTor(ia). 
En 1974, tras el asesinato de Gustavo Mejía, líder del Consejo Regional Indígena del Cauca, Taller 4 Rojo elaboró un primer cartel dedicado a este mártir, en el que su rostro abriga las movilizaciones de la organización indígena de manera semejante a como lo hace María Cano con el movimiento obrero. Originalmente, el cartel con la imagen de Mejía se incluyó en un número de la revista Alternativa (véase figura 14).
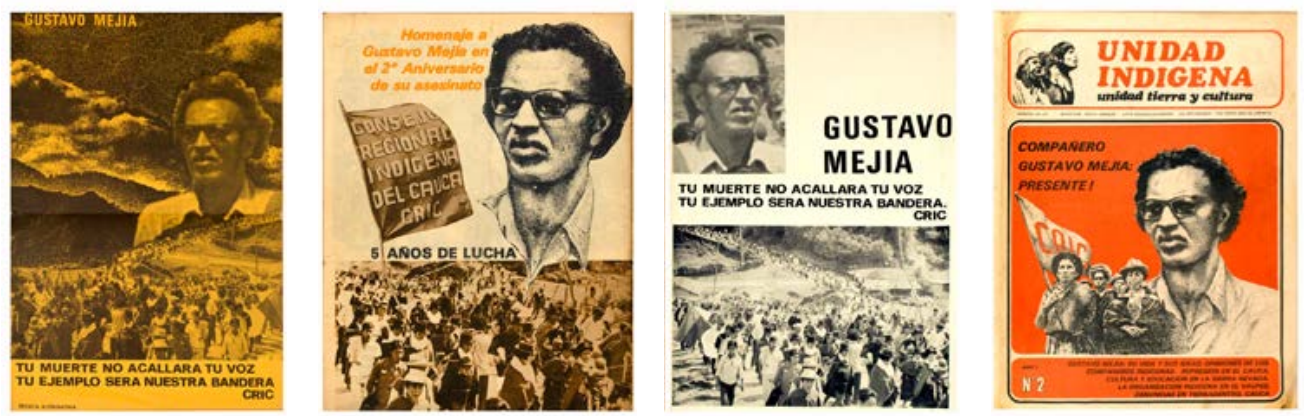

Figura 14. Carteles elaborados por el campo circundante de Taller 4 Rojo sobre el líder del Consejo Regional Indígena del Cauca Gustavo Mejía. Fuente: Cartel para la Revista Alternativa (n. ${ }^{\circ}$ 4) en homenaje a Gustavo Mejía. Diego Arango y Nirma Zárate/Taller 4 Rojo (1974). Impresión offset sobre papel, $50 \times 35 \mathrm{~cm}$.

Contracarátula Revista Alternativa (n. ${ }^{\circ}$ 72). Diego Arango, Nirma Zárate y Jorge Mora/Taller 4 Rojo (1976). Impresión offset sobre papel, $35 \times 25$ cm. Cartel para la Revista Unidad Indígena (n. ${ }^{\circ}$ ) en homenaje a Gustavo Mejía. Diego Arango y Nirma Zárate (1974). Offset sobre papel,

$50 \times 35 \mathrm{~cm}$.

Cartel de difusión para la Revista Alternativa $\left(n{ }^{\circ} 4\right)$ sobre el asesinato de Gustavo Mejía. Taller 4 Rojo (atribuido), 1974. Serigrafía sobre papel, $90 \times 60 \mathrm{~cm}$.

Al año siguiente, en 1975, meses después de la disolución del Grupo Taller 4 Rojo, Nirma Zárate y Diego Arango diseñaron el primero de varios carteles en torno a la figura de Luis Carlos Cárdenas, líder del sindicalismo independiente secuestrado y asesinado en Medellín en 1973 cuando ejercía como vicepresidente de Sintradepartamento (Comité de Solidaridad con los Presos Políticos, 1974). Realizados bajo el nombre de Taller Causa Roja, estos trabajos buscaron perpetuar la imagen del sindicalista al involucrar su figura en varios materiales de difusión y propaganda que apoyaban actividades sindicales y del Comité de Solidaridad de Presos Políticos (véase figura 15).
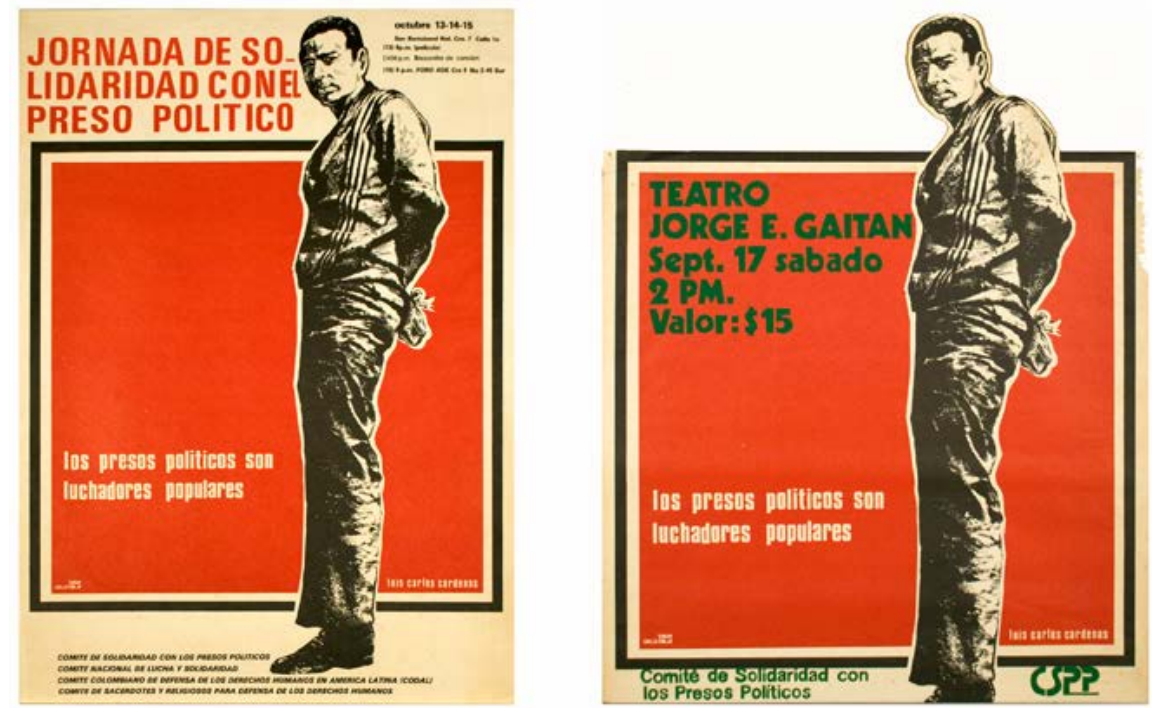

Figura 15. Carteles elaborados por el campo circundante de Taller 4 Rojo sobre el líder sindical de Sintradepartamento Luis Carlos Cárdenas.

Fuente: Cartel de difusión para Jornada de Solidaridad con el Preso Político. Taller Causa Roja (Diego Arango y Nirma Zárate), 1976. Impresión offset sobre papel, $70 \times 50 \mathrm{~cm}$

Modificación al cartel de difusión para Jornada de Solidaridad con el Preso Político. Taller Causa Roja (Diego Arango y Nirma Zárate), 1976. Impresión offset y serigrafía sobre papel, $60 \times 50 \mathrm{~cm}$. 
En gran medida, todos estos trabajos representan la necesidad del grupo de recuperar e instaurar figuras locales como referentes para las luchas y los procesos de descolonización, por medio de estrategias visuales en las que confluyen en simultáneo algunos recursos narrativos provenientes de la vanguardia rusa y del realismo socialista chino. Nos referimos, por ejemplo, al uso de imágenes de multitudes, sin distinciones de género y edad, que protagonizan la sublevación popular y que coinciden con la narrativa de algunas películas de Serguei Eisenstein (El acorazado Potemkin [1925], por ejemplo), pero también con el propósito planteado por Mao en el foro de Yenán (Tse-Tung 1972, 70) de representar a todas las clases obreras en las obras literarias y artísticas de la Revolución Cultural China. No obstante, en la serie América 73, el grupo acude a una representación de diferentes sectores de la sociedad (revolucionarios o reaccionarios), para hacer explícito quiénes apoyaban la transformación y quiénes procuraban detenerla (la clase obrera, campesina y popular son protagonistas del cambio, y los burgueses, aristócratas y representantes del cristianismo oficial u ortodoxo son agentes represores), así como al uso de tramas o filtros de color en las estampas que diferencian zonas de una imagen para resaltar otras, y construir una narrativa en tiempos, realidades presentes y deseos futuros, como sucede en Proclama a los colombianos.

\section{CIRCULACIÓN Y APROPIACIÓN}

De cualquier manera, el tema, la retórica y la técnica con que fueron resueltas estas imágenes facilitaron esa circulación fuera del campo del arte que cobró la producción de Taller 4 Rojo a la que nos hemos referido. La técnica en que fue realizado el cartel de María Cano permitió una disposición de circulación masiva, ya que la estampa circuló ampliamente a través de Voz del pueblo, órgano de difusión del Partido Comunista Colombiano; sin embargo, este cartel también fue presentado en la Primera Bienal de Artes Gráficas de Cali en 1971, lo cual da cuenta de la participación en espacios convencionales del arte que los integrantes de Taller 4 Rojo mantuvieron inicialmente. ${ }^{13}$ Por el contrario, el último de los carteles que hemos señalado, dedicado a Luis Carlos Cárdenas e impreso también masivamente en offset, según nuestra pesquisa, fue distribuido, principalmente, en organizaciones sociales y sindicales $y$, particularmente, en aquellas que se encontraban vinculadas al Comité de Solidaridad con los Presos Políticos. Las coordenadas temporales de estos dos carteles dejan comprender una parte del curso histórico en torno a Taller 4 Rojo, pues ambos fueron realizados por Diego Arango y Nirma Zárate, justo antes y justo después del lapso en que Taller 4 Rojo se consolidó y estuvo integrado de la manera más amplia. Pero más allá de las coordenadas que proponen estas dos piezas para identificar la trayectoria del colectivo, tal curso constata aquel proceso de desvinculación del campo del arte al que nos hemos referido: mientras que hasta hace pocos años la única reproducción del cartel dedicado a María Cano se encontraba en el catálogo de la Primera Bienal de Artes Gráficas de Cali, ejemplares del cartel dedicado a Cárdenas aún penden de las paredes de la sede del Comité de Presos Políticos en Bogotá y de la oficina de Sintradepartamento en Medellín, de manera semejante a como fueron usadas muchas de estas imágenes en aquella época (véase figura 16). 

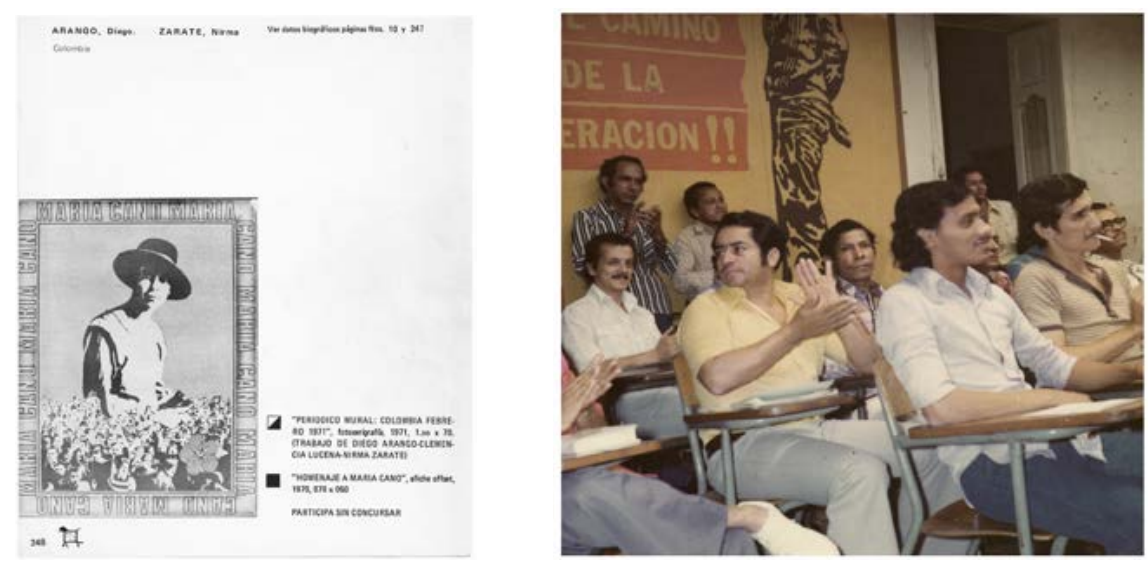

Figura 16. Página interior de la Exposición Panamericana de Artes Gráficas de Cali. (1970) y fotografía del archivo de la Escuela Nacional Sindical (Medellín), que dan cuenta de la circulación de las imágenes elaboradas por Taller 4 Rojo. Fuente: Página 248 del catálogo de la Primera Bienal Panamericana de Artes Gráficas de Cali.

Museo de Arte Moderno La Tertulia (1971). Impresión offset sobre papel, $18 \times 18 \mathrm{~cm}$

Reunión en el auditorio Luis Carlos Cárdenas de Sintradepartamento. Anónimo (ca. 1978). Fotografía 35 mm. Archivo Sintradepartamento.

Justamente, durante el proceso de investigación que desarrollamos, nos planteamos la necesidad de rastrear la circulación de este tipo de materiales en organizaciones sindicales y sociales que habían sido señaladas por los artistas en nuestras conversaciones. Encontramos material fotográfico publicado en prensa sobre acciones de estas agremiaciones donde figuran algunos materiales realizados en la plataforma creativa de Taller 4 Rojo y, también, logramos recuperar testimonios de sindicalistas y educadores que recuerdan la circulación de algunas de estas imágenes en sus circuitos.

Respecto de la primera condición, la circulación del afiche dedicado a Gustavo Mejía en la Revista Alternativa facilitó que este material se incorporara en acciones del movimiento indígena. Así lo manifiestan algunos registros fotográficos incluidos en artículos de la misma revista donde se alcanzan a ver algunos ejemplares pegados en sedes de organizaciones indígenas y campesinas. Más adelante se elaboraron nuevas versiones del afiche que fueron incluidas en el periódico Unidad Indígena como portada o como anexo para su difusión (véase figura17).
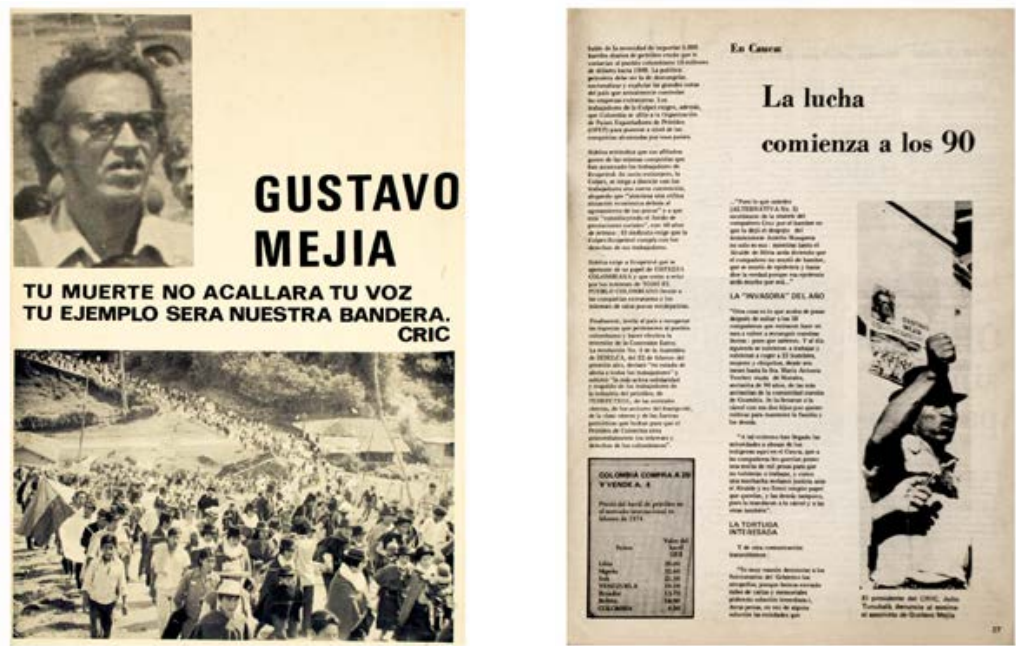

Figura 17. Cartel sobre Gustavo Mejía y página interior de Revista Alternativa que dan cuenta de la circulación de las imágenes elaboradas por Taller 4 Rojo.

Fuente: Página 27 de la Revista Alternativa (n. ${ }^{\circ}$ 4). Diego Arango, Nirma Zárate y Jorge Mora/Taller 4 Rojo (1974). Impresión offset sobre papel, $35 \times 25 \mathrm{~cm}$. Cartel de difusión para la Revista Alternativa (n. $\left.{ }^{\circ} 4\right)$ sobre e asesinato de Gustavo Mejía. Taller 4 Rojo (atribuido), 1974. Serigrafía sobre papel, $90 \times 60 \mathrm{~cm}$. 
Para la misma época, junto con otros activistas de derechos humanos, Diego Arango y Nirma Zárate apoyaron la huelga de los trabajadores de la textilera Vanitex, y elaboraron un afiche que presenta a una familia - madre, padre e hijo - apoyando el trabajo de la mujer, una de las tantas trabajadoras de la empresa. El afiche circuló ampliamente e, incluso, fue usado en la Revista Alternativa para acompañar las noticias de la huelga que duró más de seis meses. Esta imagen también apareció en la contraportada de una publicación promovida por los activistas, en la que los mismos trabajadores cuentan la historia y las dificultades vividas en la huelga, con el fin de socializar la experiencia y enriquecer los procesos de otros sindicatos; es decir, la estampa hace parte de la memoria e historia de aquella lucha. La circulación de este motivo familiar estuvo activa entre 1976 y 1979 (véase figura 18).
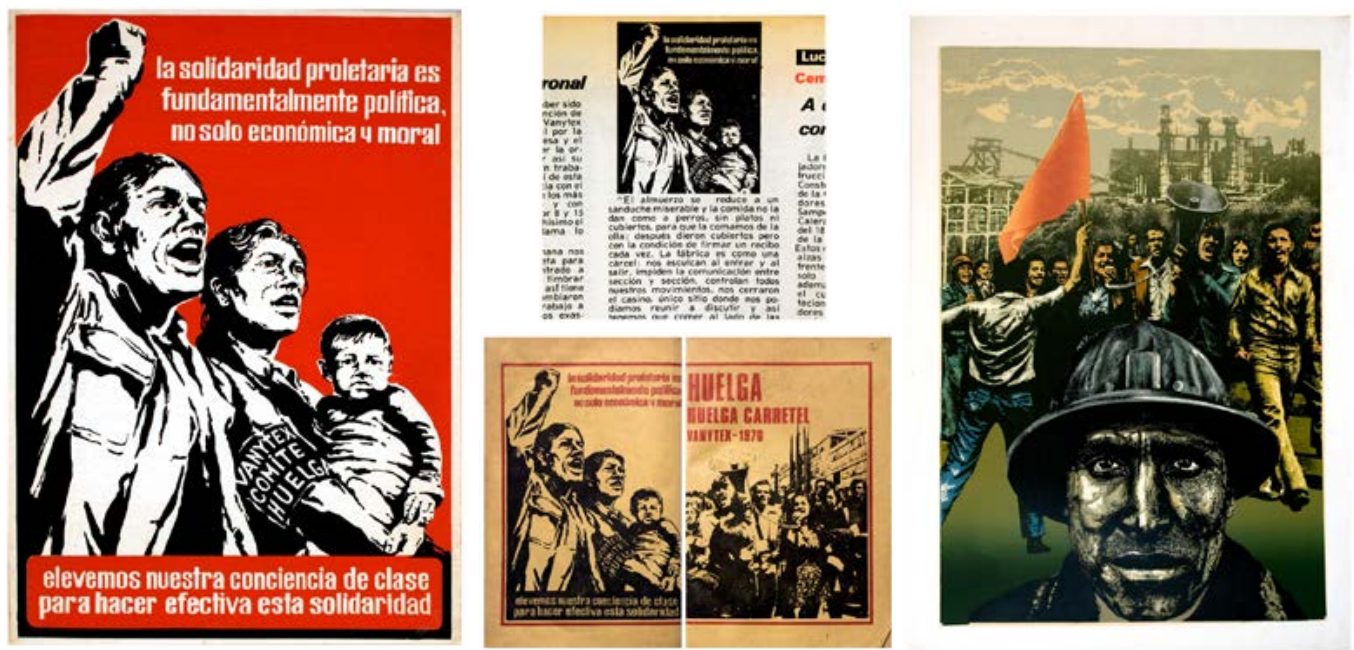

Figura 18. Cartel de apoyo a la huelga de Vanitex, página interior de la Revista Alternativa y portada del folleto que documenta la huelga; estampa $A$ la huelga 100, a la huelga 1000 (Nirma Zárate y Diego Arango, 1976)

Fuente: Cartel de difusión sobre la huelga de Vanitex. Taller Causa Roja (Diego Arango y Nirma Zárate y otros (ca. 1976). Serigrafía sobre papel, $70 \times 50 \mathrm{~cm}$. Portada del boletín Huelga Carretel Vanitex (1976), impresión offset sobre papel (Ediciones En Marcha, 2. ${ }^{a}$ ed., 1978).

Fotografía del cartel de Vanitex publicada en la Revista Alternativa (n. $\left.{ }^{\circ} 83,1976\right)$.

A la huelga 100 a la huelga 1000 (Diego Arango y Nirma Zárate/Taller Causa Roja, 1978). Fotoserigrafía sobre papel, $100 \times 70$ cm).

Por otra parte, el cartel sobre Luis Carlos Cárdenas fue posteriormente apropiado un sinnúmero de veces para la elaboración de afiches y vallas que sirvieron para la difusión de eventos de Sintradepartamento. Pensar en Luis Carlos Cárdenas permite pensar la historia de esta organización sindical: él fue uno de sus fundadores; su figura es conmemorada en el cartel de Causa Roja; ese cartel sirvió para diseñar una valla que aparece en los registros fotográficos de una convención de la antigua sede del sindicato; el auditorio en la sede de este, hoy sede de la Escuela Nacional Sindical, lleva su nombre; y en ese auditorio hay un mural pintado por Nirma Zárate en 1982 donde él es el protagonista central.

\section{TESTIMONIOS}

A través de diálogos con activistas de derechos humanos que impulsaron acciones directas en conjunto con miembros de Taller 4 Rojo durante la década de 1970, logramos contactar algunos afiliados a Sintradepartamento de aquella época, que conocían el proceso del mural y habían participado de la interlocución creativa con Taller 4 Rojo. Gracias al 
diálogo que establecimos con algunos de estos sindicalistas (pensionados hoy), identificamos varios personajes que figuran en el mural y que correspondían a figuras que Taller 4 Rojo había registrado en su producción visual como el propio Cárdenas, María Cano, Camilo Torres, Quintín Lame, Gustavo Mejía, Liberato Crespo y otros más. En ese mismo recinto, estuvieron colgadas por más de cuatro décadas algunas obras de Taller 4 Rojo que nuestros interlocutores recordaban y describían con entusiasmo (véase figura 19).
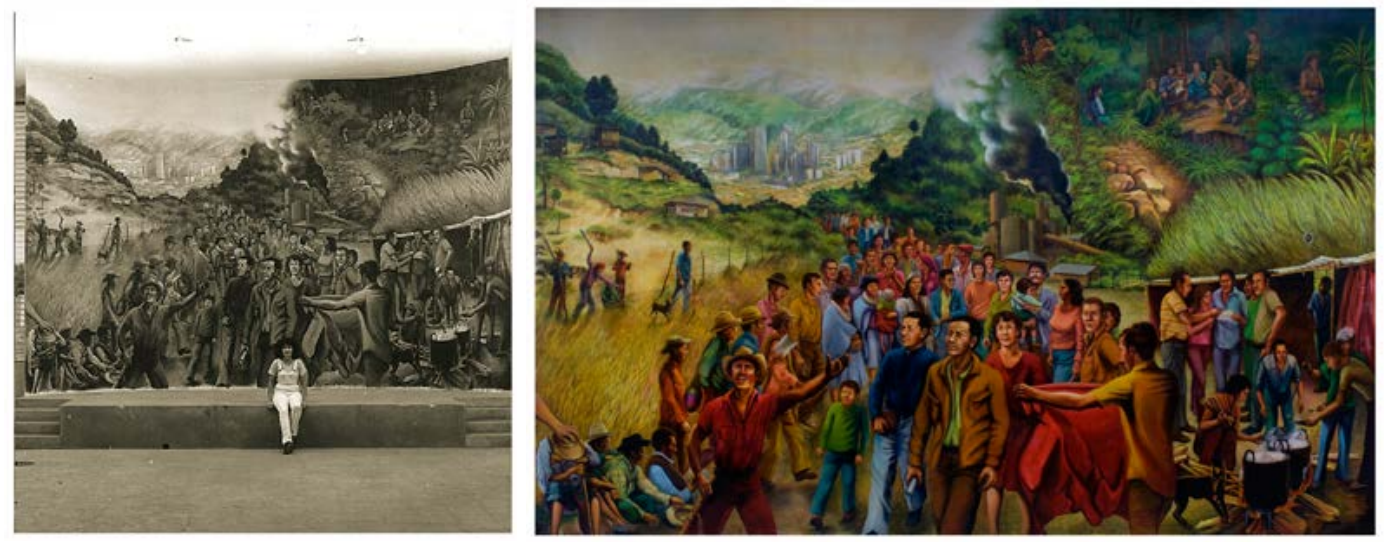

Figura 19. Fotografía de Nirma Zárate delante de su mural en el auditorio Luis Carlos Cárdenas del edificio de Sintradepartamento en Medellín; fotografía del mural en el mismo edificio, hoy Escuela Nacional Sindical.

Fuente: Nirma Zárate frente a su mural en el auditorio de Sintradepartamento. Anónimo (ca. 1981). Fotografía 35 mm. Archivo particular.

Mural en la sede de Sintradepartamento, actual sede de la Escuela Nacional Sindical. Nirma Zárate (con la colaboración de Teresa Quiñones, Felipe

Larrea y Alexis Forero), 1981. Acrílico sobre muro. Archivo particular.

Cuando visitamos por primera vez la sede actual de la Escuela Nacional Sindical en Medellín en 2012, nos encontramos el tríptico en fotoserigrafía dedicado a la resistencia del pueblo vietnamita ante la invasión norteamericana, realizado por Taller 4 Rojo en 1972; las estampas enmarcadas se encontraban puestas temporalmente en el piso de una sala que estaba en mantenimiento. Luego, cuando entrevistamos a algunos sindicalistas, sorprendentemente, sin necesidad de revisar fuente visual alguna, nos describieron y narraron la disposición retórica de dichas estampas y las localizaron en relación con los procesos de los que participaban en el sindicato. Además, gracias a estos diálogos, también logramos identificar fotografías de convenciones sindicales de las décadas de 1980 y 1990 realizadas en el auditorio Luis Carlos Cárdenas, mencionado atrás, que dejan ver las estampas colgadas en las paredes (véase figura 20).
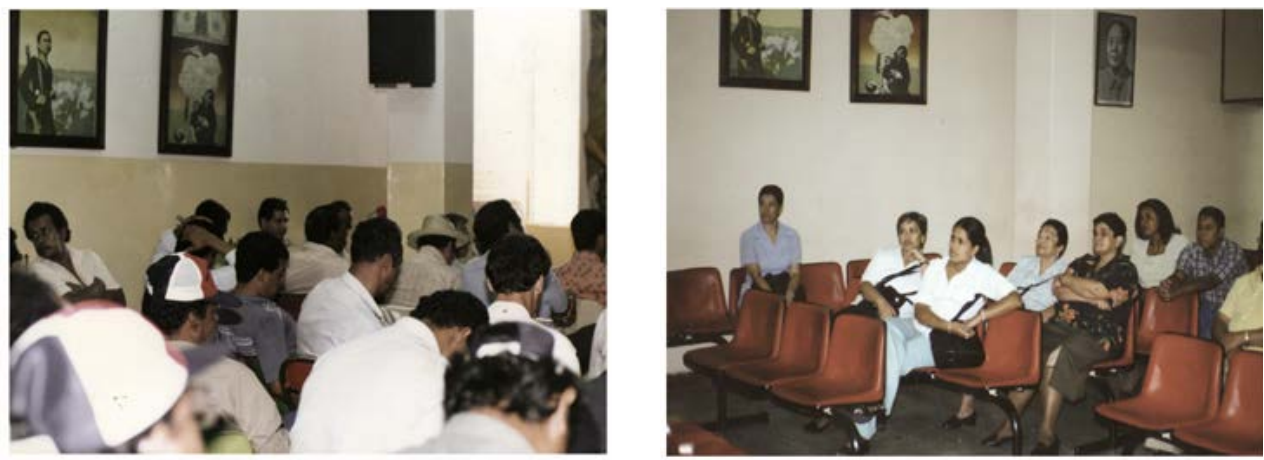

Figura 20. Fotografías en Sintradepartamento.

Fuente: Reunión en el auditorio Luis Carlos Cárdenas de Sintradepartamento. Anónimo (ca. 1978l. Fotografía 35 mm. Archivo particular. Reunión en el auditorio Luis Carlos Cárdenas de Sintradepartamento. Anónimo (ca. 1978). Fotografía 35 mm. 
Paralelo a la investigación y la exposición, algunos colegas y amigos nos mencionaron cómo conocieron o recordaban este tríptico sobre la resistencia del pueblo de Vietnam. El historiador del arte Álvaro Medina (comunicación personal), por ejemplo, nos relató que esas imágenes circularon ampliamente en la década de 1970 y fueron muy populares; pues, por un lado, representaban un tema con el que simpatizaban muchas personas, incluso sin ser abiertamente de izquierda: la resistencia de Vietnam; y por otro, porque Zárate y Arango las dispusieron comercialmente a un precio cómodo, motivados más por su circulación que por la ganancia económica. Medina mismo las había comprado y las tuvo en su casa, aunque ya no recordaba cuál había sido el destino de esos ejemplares, tras varias mudanzas. Por otro lado, Lucas Ospina, artista y profesor de arte, al recibir nuestra invitación para la inauguración de la curaduría de Taller 4 Rojo en Bogotá, nos respondió con interés, y apuntó algunos de sus recuerdos: "en cuanta casa de amigos de mis padres a la que me llevaban a cumpleaños y ágapes siempre estaban esas obras de Taller 4 Rojo ahí bien puestas y enmarcadas, y me intrigaba cómo uno podía comer tranquilo y frugalmente con tanta denuncia alrededor (muchas de esas casas eran en Rosales, una izquierda de caviar)" (comunicación personal).

Un año después de la segunda versión de la exposición de Taller 4 Rojo presentada en el Museo de Arte Moderno de Medellín, sorpresivamente, sin proponérnoslo, nos encontramos con las estampas de Vietnam en junio de 2013 en un pueblito al sur de Colombia llamado Pitalito. Estaban colgadas en las paredes de las escaleras de una casa hotel. Al preguntar a uno de los dueños sobre la procedencia de las piezas, no dudó en decir que eran de origen vietnamita, que probablemente las había conseguido su padre en la década de 1980 cuando militaba en el Movimiento Obrero Independiente Revolucionario. Añadió que en esa época era frecuente la circulación y el intercambio de afiches y carteles de propaganda revolucionaria importados desde China. En suma, el campo de circulación de estos ejemplares terminó por otorgarle, accidentalmente, un origen exógeno que, no obstante, cobra sentido ante la necesidad de apoyo intercontinental propio de aquella época, pero que, de cualquier modo, terminó por anular al autor colectivo detrás de aquellas estampas (véase figura 21).

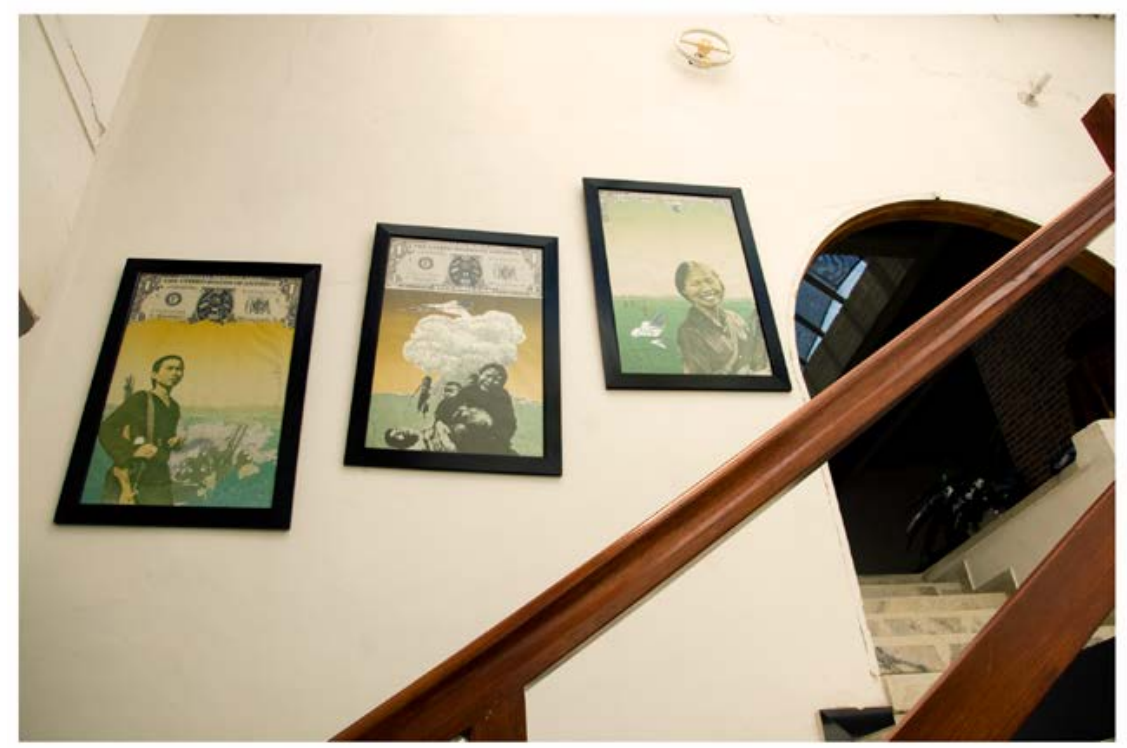

Figura 21. Hotel Ullumbé (Pitalito, Huila).

Fuente: Ejemplares de las estampas que componen la Trilogía sobre Vietnam (Diego Arango y Nirma Zárate/Taller 4 Rojo, 1972. Serigrafía sobre papel, $100 \times 70 \mathrm{~cm}$ ) en el Hotel Uyumbe en Pitalito (Huila). 
Esta diversidad de testimonios y anécdotas dan cuenta de cómo una de las primeras y más conocidas estampas de Taller 4 Rojo que se presentaron por primera vez en la exposición de Colombia en la Bienal de Venecia de 1972, reproducidas en varias publicaciones desde hace cuatro décadas, y conservadas en varias colecciones públicas en Bogotá, también circularon fuera del campo especializado del arte y ha interpelado a diversos actores en los lugares más recónditos del territorio colombiano: artistas, intelectuales, sindicalistas, trabajadores y militantes de izquierda son apenas unos ejemplos de los que nuestra investigación pudo rastrear.

A su vez, la persistencia en torno a algunas de las figuras políticas referidas en las estampas del taller, ha dejado — como las vietnamitas - una huella indeleble en muchos activistas e integrantes de movimientos sociales de Colombia. Tal persistencia visual solo fue evidente para nosotros ante la construcción del archivo digital y un trabajo de catalogación arduo, en el que describimos cada uno de los materiales encontrados: estampas, pruebas de estado, fotografías y artículos de revistas, entre otros. Con ellos empezamos a percibir las múltiples reiteraciones, reproducciones y apropiaciones operadas por Taller 4 Rojo.

Asimismo, fue emocionante encontrar cómo nuevos relatos y testimonios de algunos activistas, sindicalistas y artistas fueron surgiendo gracias a la exhibición del archivo que articula la curaduría. De modo que la recuperación e identificación del amplio repertorio de documentos, estados de prueba, fuentes fotográficas, páginas de revistas, publicaciones independientes y estampas firmadas han sido fundamentales para hacer una lectura inédita de Taller 4 Rojo. A través de la articulación de ese archivo, informe y disperso hasta antes de la exposición, nos ha sido posible comprender el rol que adquirieron varias estampas del colectivo como editoriales visuales y dispositivos de representación de personajes y mártires políticos de la historia de Colombia; además, con él fue posible comprender los campos de circulación y la forma como públicos diversos han sido interpelados desde entonces; y por último, demuestra la supervivencia de su producción en la memoria de varias generaciones de colombianos que han participado en la continua reformulación de las formas de imaginación política desde hace más de cuarenta años.

\section{NOTAS}

1 Dadas las características de la curaduría, una práctica artística que entendemos como una plataforma de investigación creativa que comúnmente resulta en un dispositivo museográfico, en un sistema de exposición, comprendemos estos "fondos documentales" como un conjunto de materiales diversos, no restringidos al documento escrito, sino enriquecido por matrices visuales, audiovisuales, artísticas y sonoras, entre otras, que simultáneamente pueden desempeñar el papel de fuente documental para el desarrollo de una investigación, que sustenta y cobra un lugar en la disposición museográfica de la exposición.

2 No deja de llamar la atención que ambos proyectos, el Atlas Mnemosyne, de Aby Warburg, y el proyecto de los pasajes de Benjamin, hayan resultado en estados parcialmente presentados por sus autores y, por eso, los comprendamos como inacabados, asunto que bien sirve para comprender el archivo como un texto abierto, que permite el desarrollo de múltiples relatos según la disposición de los materiales que incluye, condición que resulta recurrente en las prácticas curatoriales. 
3 Del mismo modo resulta el rol de la fotografía en el proyecto de los pasajes de Benjamin como recurso para conformar un dispositivo de exposición, asunto del que varios autores se han ocupado en las últimas décadas, entre ellos, Buck-Morss (1995).

4 En estas curadurías, apelamos a estrategias de "montaje" o de "collage" (Benjamin), en las cuales las imágenes proponen una narrativa particular que cada espectador construye y recrea de acuerdo con su sensibilidad y experiencia. Sin embargo, como algo independiente de la curaduría, nos interesa escribir un relato a manera de "visita comentada" que permita en una instancia de lectura ver algunas relaciones que queríamos enunciar al construir esos conjuntos. Ver: Barón Pino, María Sol y Camilo Andrés Ordóñez Robayo. 2014. Rojo y más Rojo. Taller 4 Rojo: producción gráfica y acción directa. Bogotá: Fundación Gilberto Alzate Avendaño.

5 Yates (1974) se ha encargado de considerar diferentes prácticas nemotécnicas que favorecen la relación entre retórica, imágenes y rememoración; entre estas, el "teatro de la memoria" bien podría cobrar relaciones con las prácticas de Benjamin y Warburg como con la dimensión discursiva de la curaduría, pues, justamente, aquella consiste en una sugestión mental que invita al orador a imaginar un espacio físico ocupado con un conjunto de imágenes que puede seguir en un orden narrativo, para fabricar su relato como un antiguo cicerone, el guía que interpretaba su discurso según la disposición de un conjunto de obras en una sala de exposiciones.

6 Basta mencionar que durante esa década tres museos de arte moderno abrieron sus puertas en algunas ciudades (Barranquilla, Cartagena y Medellín), mientras que los dos que existían en Cali y Bogotá se renovaron. Paralelamente, en Bogotá, se inauguraron tres sedes para museos de arte contemporáneo: el Museo de Arte Contemporáneo el Minuto de Dios, el Museo de Arte de la Universidad Nacional y el Museo de Arte Actual de la Fundación Gilberto Alzate Avendaño.

7 La mayoría de los autores convocados por Salvat y coordinados por Eugenio Barney hacían parte de instituciones académicas; sin embargo, el proyecto editorial estuvo dirigido al público general, lo cual justificó el uso de un lenguaje coloquial y sencillo, así como un sistema de entregas capitulares por fascículos que estimulaban la expectativa del consumidor y facilitaban la compra de cada segmento a un bajo costo.

8 Entre ellas, y con el propósito de mencionar las que han sido un referente importante para nuestras investigaciones, se encuentran la de Carmen María Jaramillo y John Castles Re-vista años 70 realizada en 2002 en la sala de exposiciones de la Facultad de Artes ASAB de la Universidad Distrital Francisco José de Caldas, que partió de la investigación consignada en Fisuras del arte moderno (Jaramillo 2012); las de María lovino sobre Fernell Franco, Óscar Muñoz y Bernardo Salcedo al inicio de este milenio, a las que les corresponden sendos documentos publicados como libros o catálogos; y las más recientes Hernán Díaz revelado: retratos, sesiones y hojas de contactos y Autorretrato disfrazado de artista: arte conceptual y fotografía en Colombia, exhibidas en las salas del Banco de la República y la Biblioteca Luis Ángel Arango en 2015, curadas por Santiago Rueda Fajardo, y que también se originan en la investigación que emprendió desde hace una década La fotografía en Colombia en la década de los setenta (2014).

9 De hecho, este crecimiento en la investigación y producción editorial sobre el campo del arte en Colombia puede coincidir con el momento en que aparecieron las primeras cátedras de arte por iniciativa del profesor Álvaro Medina en la Escuela de Bellas Artes en la Universidad Nacional.

10 Entre estas publicaciones, se encuentra el capítulo de Germán Rubiano (1977) "La figuración política" (Historia del arte colombiano. Bogotá: Salvat), y varios de los catálogos de exposiciones donde participaron integrantes de Taller 4 Rojo como el de la Bienal de Venecia de 1972 y el de la Segunda Bienal de San Juan del Grabado Latinoamericano de 1972, la Exposición Panamericana de Artes Gráficas en 1970 y la Primera Bienal Americana de Artes Gráficas de Cali de 1971.

11 Entre las monografías inéditas que abordaban la trayectoria del colectivo, consultamos durante la investigación la monografía de Wiston Porras (2009). Pronto nos enteramos de que, en paralelo a nuestro trabajo, Alejandro Gamboa terminaba de realizar la segunda monografía sobre el colectivo, en la que profundizó sobre las convicciones políticas que impulsaron a los integrantes de Taller 4 Rojo, la cual fue publicada en 2011 por la Secretaría Distrital de Cultura, Recreación y Deporte de Bogotá. Posterior a nuestra curaduría e investigación, se publicó el libro Arte y disidencia política: memorias del Taller 4 Rojo, del Taller de Historia Crítica del Arte (2015).

12 Hablamos de campo circundante para dar cuenta de la constelación de artistas, productores visuales, académicos y activistas sociales cercanos o partícipes temporalmente de la plataforma intelectual y artística del colectivo. Por ejemplo, la cercanía de Jorge Villegas, Germán Rojas o Salomón Kalmanovitz en ciertos proyectos y acciones del colectivo.

13 En la investigación y en las decisiones curatoriales, reconsideramos estas circunstancias cuando decidimos elaborar una edición facsimilar del cartel de María Cano para su distribución gratuita durante la segunda versión de la exposición realizada en Medellín en 2013. 


\section{REFERENCIAS}

Barón Pino, María Sol y Camilo Andrés Ordóñez Robayo. "Plataformas de producción para la historia del arte colombiana: de la Historia del arte colombiano de Salvat al Instituto de Investigaciones Estéticas, y viceversa". Presentación en XXXIX Coloquio Internacional de Historia del Arte, Universidad Nacional Autónoma de México, México, octubre 19, 2015. Consultado febrero 10, 2017. https://www.youtube. com/watch?v=gXdRnaFbAy4

Barón Pino, María Sol y Camilo Andrés Ordóñez Robayo, en prensa. Múltiples y originales. Arte y cultura visual en Colombia: años 70. Bogotá: Pontificia Universidad Javeriana.

Barón Pino, María Sol y Camilo Andrés Ordóñez Robayo. 2011a. “Postales audiovisuales: exotismo, turismo y Pa' Colombia". Calle14 5 (7): 78-93.

Barón Pino, María Sol y Camilo Andrés Ordóñez Robayo. 2011b. “Taller 4 Rojo era un taller de artes gráficas." Consultado febrero 10, 2017. http://www.transhistoria.laveneno.org/imagenes/T4Rera.jpg

Barón Pino, María Sol y Camilo Andrés Ordóñez Robayo. 2014. Rojo y más Rojo. Taller 4 Rojo: producción gráfica y acción directa. Bogotá: Fundación Gilberto Alzate Avendaño.

Buck-Morss, Susan. 1995. Dialéctica de la mirada: Walter Benjamin y el proyecto de los pasajes. Madrid: Antonio Machado Libros.

Comité de Solidaridad de Presos políticos. 1974. Libro negro de la represión: Frente Nacional 1958-1974. Comité de Solidaridad de Presos Políticos.

Eisenstein, Sergei M. 1925. El acorazado Potemkin. Unión Soviética: Goskino, DVD.

Gamboa Medina, Alejandro. 2011. El Taller 4 Rojo: entre la práctica artística y la lucha social. Bogotá: Instituto Distrital de las Artes.

Iriarte, María Elvira. 1986. Historia de la serigrafía en Colombia. Bogotá: Universidad Nacional de Colombia. Jaramillo, Carmen María. 2012. Fisuras de arte moderno en Colombia. Bogotá: Alcaldía Mayor de Bogotá.

Lame Chantre, Manuel Quintín. 1973. Las luchas del indio que bajó de la montaña al valle de la "civilización". Editado por Gonzalo Castillo Cárdenas. Bogotá: Rosca de Investigación y Acción Social.

Medina, Álvaro. 1978. Procesos del arte en Colombia. Bogotá: Colcultura.

Porras, Wiston. "Taller 4 Rojo 1970-1975: imagen impresa e imagen artística". Tesis de maestría, Universidad Pedagógica y Tecnológica de Colombia, Tunja, 2009.

Rubiano, Germán. 1977. La figuración política. Vol. 7 de Historia del arte colombiano. Bogotá: Salvat.

Rueda Fajardo, Santiago. 2014. La fotografía en Colombia en la década de los setenta. Bogotá: Universidad de los Andes.

Salvat, ed. 1977. Enciclopedia Historia del arte colombiano. Tomo I y II. Bogotá: Salvat Editores Colombiana, S.A

Taller Historia Crítica del Arte. 2015. Arte y disidencia política: memorias de Taller 4 Rojo. Bogotá: La Bachué.

Traba, Marta. 1976. Mirar en Bogotá. Bogotá: Colcultura.

Tse-Tung, Mao. 1972. Obras escogidas de Mao Tse-Tung. Pekín: Ediciones en Lenguas Extranjeras.

Yates, Frances A. 1974. El arte de la memoria. Madrid: Taurus.

\section{FILMOGRAFÍA}

Pa' Colombia. 1971 - 1979. Dirigida por: Carlos Lersundy. 16 mm, color, 14 minutos. 


\section{FOTOGRAFÍAS}

Anónimo. 1973 . Fotografía de Manuel Quintín Lame. En Las luchas del indio que bajó de la montaña al valle de la "civilización". (Jorge Mora, ca. 1973).

- (ca. 1978). Reunión en el auditorio Luis Carlos Cárdenas de Sintradepartamento. Fotografía 35 mm. Archivo particular.

- (ca. 1981). Nirma Zárate frente a su mural en el auditorio de Sintradepartamento. Fotografía 35 mm. Archivo particular.

- 1972. Intervención en la Universidad de los Andes con obras del Grupo Taller 4 Rojo. Fotografía a color $35 \mathrm{~mm}, 9 \times 12 \mathrm{~cm}$.

Mora, Jorge. (ca. 1973). Fotografía empleada en carátula. 1973. En Las luchas del indio que bajó de la montaña al valle de la "civilización". Fotografía en blanco y negro $35 \mathrm{~mm}$.

— 1974. Manifestación en la Plaza de Bolívar en Bogotá. Fotografía 35 mm.

Grupo Taller 4 Rojo (ca. 1972). Fotografía en la Escuela Taller 4 Rojo. Fotografías lith, 6x $8.5 \mathrm{~cm}$

\section{MATERIAL GRÁFICO Y PUBLICITARIO}

“Belisario presidente Colombia te aclama". 1970. Propaganda publicada en El Espectador, 9 de abril, $9 \mathrm{~A}$.

"Colombiano: Vote el 19 de abril". 1970. Propaganda del Ministerio de Educación Nacional publicada en Revista Cromos, n. ${ }^{\circ}$ 2725, 16 de marzo: 28.

“Colombianos al poder con Rojas". 1970. Propaganda publicada en Semanario Alerta, 5 de abril.

"Convocatoria! Exposición Panamericana de Artes Gráficas". 1970. Pauta publicada en El Espectador 20 de septiembre. Archivo Museo La Tertulia (Cali).

"Enamórese de su Colombia". 1973. Corporación Nacional de Turismo. Propaganda publicada en la revista Colombia.

"Ganarás con el sudor de tu frente". 1970. Propaganda publicada en El Espectador, 16 de abril: 1A.

“Una imagen nueva...!". 1967. Publicidad de la organización Hotelera Germán Morales e Hijos Ltda., publicada en revista Diners, n. ${ }^{\circ} 67$, febrero.

Arango, Diego y Nirma Zárate (Grupo Taller 4 Rojo). 1974. Cartel para la revista Alternativa (n. ${ }^{\circ}$ 7) en apoyo al movimiento estudiantil. Impresión offset sobre papel, $50 \times 35 \mathrm{~cm}$.

Arango, Diego y Nirma Zárate (Grupo Taller 4 Rojo). 1974. Cartel para la Revista Alternativa (n. ${ }^{\circ}$ ) en homenaje a Gustavo Mejía. Impresión offset sobre papel, $50 \times 35 \mathrm{~cm}$. Archivo particular.

Arango, Diego y Nirma Zárate (Taller Causa Roja). (ca. 1976). Cartel de difusión sobre la huelga de Vanitex. Serigrafía sobre papel, $70 \times 50 \mathrm{~cm}$.

Arango, Diego y Nirma Zárate (Taller Causa Roja). 1976. Cartel de difusión para Jornada de Solidaridad con el Preso Político. Impresión Offset sobre papel, $70 \times 50 \mathrm{~cm}$.

Arango, Diego y Nirma Zárate (Taller Causa Roja). 1976. Modificación al cartel de difusión para Jornada de Solidaridad con el Preso Político. Impresión offset y serigrafía sobre papel, $60 \times 50 \mathrm{~cm}$.

Arango, Diego y Nirma Zárate. 1974. Cartel para la Revista Unidad Indígena $\left(\mathrm{n} .{ }^{\circ} 2\right)$ en homenaje a Gustavo Mejía. Offset sobre papel, $50 \times 35 \mathrm{~cm}$.

Arango, Diego, Nirma Zárate y Jorge Mora (Grupo Taller 4 Rojo). 1974. Revista Alternativa n. ${ }^{\circ} 4: 27$. Impresión offset sobre papel, $35 \times 25 \mathrm{~cm}$.

Arango, Diego, Nirma Zárate y Jorge Mora (Taller 4 Rojo). 1976. Contracarátula Revista Alternativa, n. 72. Impresión offset sobre papel, $35 \times 25 \mathrm{~cm}$. 
Barrios, Alvaro. 1972. Ejemplar de la serie Tres generaciones de buen café. Publicado en Diario del Caribe. Barranquilla, 17 de junio. Impresión offset sobre papel, $39 \times 23 \mathrm{~cm}$ c/u. Colección Museo de Arte Moderno de Bogotá.

Catálogo de la Primera Bienal Panamericana de Artes Gráficas de Cali. 1971. Museo de Arte Moderno La Tertulia, 248. Impresión offset sobre papel, $18 \times 18 \mathrm{~cm}$.

Catálogos de la I y II Bienal Americana de Artes Gráficas. 1971, 1973. Biblioteca Museo de Arte Moderno de Bogotá.

Giangrandi, Umberto, Carlos Granada y Fabio Rodríguez Amaya (Taller 4 Rojo). 1974. Carpeta testimonios. Impresión offset sobre cartón plegado, $35 \times 50 \mathrm{~cm}$.

Grupo Taller 4 Rojo (atribuido), 1974. Cartel de difusión para la Revista Alternativa (n. $\left.{ }^{\circ} 4\right)$ sobre el asesinato de Gustavo Mejía. Serigrafía sobre papel, $90 \times 60 \mathrm{~cm}$.

Grupo Taller 4 Rojo (atribuido). Cartel comisionado por el MOIR para la difusión del I Encuentro de los Trabajadores del Arte Revolucionario. Fotoserigrafía sobre papel, $69.5 \times 50 \mathrm{~cm}, 1970$.

Grupo Taller 4 Rojo (ca. 1973). Cartel para la difusión del libro de Quintín Lame Las luchas del indio que bajó de la montaña al valle de la "civilización,"Serigrafía sobre papel, $90 \times 65 \mathrm{~cm}$.

Grupo Taller 4 Rojo. 1971. Cartel comisionado por el Museo de Arte Moderno de Bogotá para la difusión de la exposición Surrealismo. Fotoserigrafía sobre papel, $70 \times 50 \mathrm{~cm}$ (revés sellado).

Grupo Taller 4 Rojo. 2011. Portada del libro El taller 4 Rojo: entre la práctica artística y la lucha social de Alejandro Gamboa. Bogotá: Instituto Distrital de las Artes.

Jaramillo, Carmen María. 2004. Catálogo Revista Arte en los años setenta. Academia Superior de Artes de Bogotá.

Mora, Jorge (Grupo Taller 4 Rojo). 1973. Carátula para Las luchas del indio que bajó de la montaña al valle de la "civilización". Impresión offset sobre cartulina, $22 \times 14 \mathrm{~cm}$.

Portada del boletín Huelga Carretel Vanitex. 1976. impresión offset sobre papel. Bogotá: Ediciones En Marcha, 2. ${ }^{a}$ ed.

Registro de publicidad política pegada sobre algunos muros en calles de Bogotá. 1978. Revista Flash, n. ${ }^{\circ}$ 4, segunda etapa, 15 de febrero: 16.

\section{OBRAS ARTÍSTICAS}

Arango, Diego y Nirma Zárate (Grupo Taller 4 Rojo). 1973. Serie América I. Fotoserigrafía sobre papel, $70 \times 100 \mathrm{~cm}$.

Arango, Diego y Nirma Zárate (Grupo Taller 4 Rojo). 1973. Serie América IV. Fotoserigrafía sobre papel, $70 \times 100 \mathrm{~cm}$.

Arango, Diego y Nirma Zárate (Taller 4 Rojo). 1971. "La flor roja del trabajo" Homenaje a María Cano. Reproducción facsimilar, $70 \times 50 \mathrm{~cm}$.

Arango, Diego y Nirma Zárate (Taller 4 Rojo). 1972. Ejemplares de las estampas que componen la Trilogía sobre Vietnam. Serigrafía sobre papel, $100 \times 70 \mathrm{~cm}$. Hotel Uyumbe en Pitalito (Huila).

Arango, Diego, Nirma Zárate (Taller Causa Roja). 1978. A la huelga 100 a la huelga 1000. Fotoserigrafía sobre papel, $100 \times 70 \mathrm{~cm}$.

Barrios, Álvaro. 1972. Ejemplar de la serie Tres generaciones de buen café. Publicado en Diario del Caribe. Barranquilla, 17 de junio. Impresión offset sobre papel, $39 \times 23 \mathrm{~cm}$ c/u. Colección Museo de Arte Moderno de Bogotá.

Granada, Carlos (Grupo Taller 4 Rojo). (ca. 1973). Lápiz de color sobre papel, $47 \times 36 \mathrm{~cm}$.

Paz, Luis. 1973. Yo soy el rey y amo la ley. Fotoserigrafía sobre papel, $100 \times 70 \mathrm{~cm}$. Colección Museo de Arte Moderno de Bogotá. 
Zalamea, Gustavo. 1977. Retorna la calma. Dibujo y collage sobre página del diario El Tiempo, $70 \times 70 \mathrm{~cm}$. Colección particular.

Zárate, Nirma (con la colaboración de Teresa Quiñones, Felipe Larrea y Alexis Forero). 1981. Mural en la sede de Sintradepartamento, actual sede de la Escuela Nacional Sindical. Acrílico sobre muro. Archivo particular.

\section{REVISTAS}

Revista Arte en Colombia. 1981. n. ${ }^{\circ} 14$.

Revista del Arte y la Arquitectura. 1978. año 1, n. ${ }^{\circ} 3$.

Revista del Arte y la Arquitectura. 1981. vol. 2, n. ${ }^{\circ}$ 6: 14 y 15.

\section{Cómo citar:}

Ordóñez Robayo, Camilo Andrés y María Sol Barón Pino. 2018.

"Historiografía y curaduría: relatos visuales a partir de imágenes

de archivo". Cuadernos de Música, Artes Visuales y Artes

Escénicas 13 (2): 147-173. http://doi.org/10.11144/javeriana.

mavae13-2.hycr 